\title{
LASER SURFACE MODIFICATION OF AZ31B Mg ALLOY FOR BIO-WETTABILITY
}

YeeHsien Ho

Thesis Prepared for the Degree of

MASTER OF SCIENCE

UNIVERSITY OF NORTH TEXAS

December 2013

APPROVED:

Narendra B. Dahotre, Major Professor and Chair of the Department of Materials Science and Engineering

Sundeep Mukherjee, Co-Major Professor

Pete Collins, Committee Member Jincheng Du, Committee Member Costas Tsatsoulis, Dean of the College of Engineering

Mark Wardell, Dean of the Toulouse Graduate School 
Ho, YeeHsien. Laser surface modification on AZ31B Mg alloy for bio-wettability. Master of Science (Materials Science and Engineering), December 2013, 43 pp., 10 tables, 17 figures, references, 25 titles.

Laser surface modification of AZ31B Magnesium alloy changes surface composition and roughness to provide improved surface bio-wettability. Laser processing resulted in phase transformation and grain refinement due to rapid quenching effect. Furthermore, instantaneous heating and vaporization resulted in removal of material, leading the textured surface generation. A study was conducted on a continuum-wave diode-pumped ytterbium laser to create multiple tracks for determining the resulting bio-wettability. Five different laser input powers were processed on Mg alloy, and then examined by XRD, SEM, optical profilometer, and contact angle measurement. A finite element based heat transfer model was developed using COMSOL multi-physics package to predict the temperature evolution during laser processing. The thermal histories predicted by the model are used to evaluate the cooling rates and solidification rate and the associated changes in the microstructure. The surface energy of laser surface modification samples can be calculated by measuring the contact angle with 3 different standard liquid (D.I water, Formamide, and 1-Bromonaphthalen). The biowettability of the laser surface modification samples can be conducted by simulated body fluid contact angle measurement. The results of SEM, 3D morphology, XRD, and contact angle measurement show that the grain size and roughness play role for wetting behavior of laser processing $\mathrm{Mg}$ samples. Surface with low roughness and large grain size performs as hydrophilicity. On the contrast, surface with high roughness and small grain size performs as hydrophobicity. 
Copyright 2013

by

YeeHsien Ho 


\section{ACKNOWLEDGMENTS}

Foremost, I would like to express my sincere gratitude to my graduate advisor Dr. Narendra Dahotre. His sagacity and patience are great to me. He continually and persuasively conveyed his enthusiasm in regard to research. Without his supervision and constant encouragement this thesis would not have been finished.

I would like to thank my co-advisor Dr. Sundeep Mukherjee, who always shows his cheerfulness and willingness to direct and encourage me. I also want to thank the rest of my thesis committee members Dr. Pete Collins, Dr. Jincheng Du, for their encouragement and insightful comments.

I would like to thank Dr. Nigel Shepherd. Without his help of communicating with the graduate school, I would never have a chance to continue through graduate school during the low valley of my life. I would like to thank the previous post-Doc Dr. Sameer R. Paital and Dr. S. Santhanakrishnan, whose work demonstrated to me that how to concern the matters of research and always inspirited me to pursue to an advanced quality in experimentation and research.

I would like to thank my group fellow Hitesh Vora, who helped me to build the computational model for my thesis, to improve experiment process environment, to maintain laser instruments, and so on. Shravana Katakam and Ravi Shanker Rajamure, I will always appreciate you as my companions during my graduate time.

Last but not least, I would like to thank my wife, Agnes Hu, my parents, New-Jing Ho and Jui-Chu Fan, my parents in law, Ming-Zong $\mathrm{Hu}$ and Siou Rong $\mathrm{Hu}$, and all of the Christian saints at the Church in Denton. You are my greatest support, having my back, for me to finish my MS. 


\section{TABLE OF CONTENTS}

Page

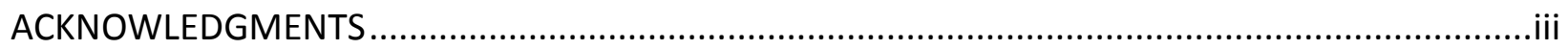

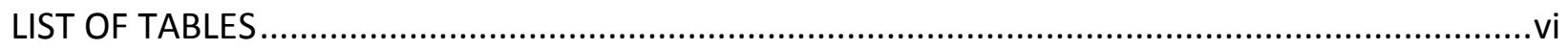

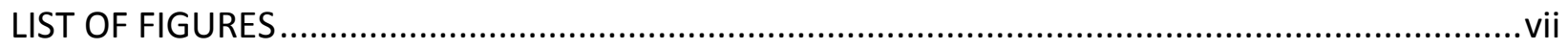

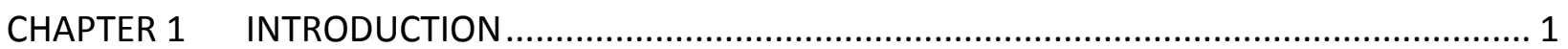

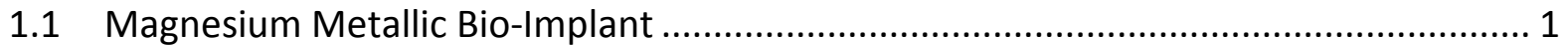

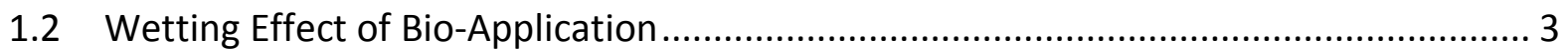

1.3 Surface Modification Technique for Bio-Application .......................................... 4

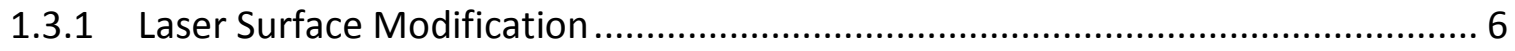

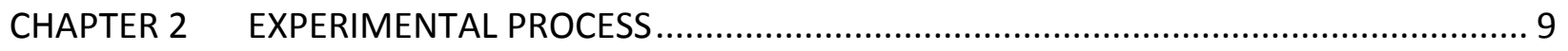

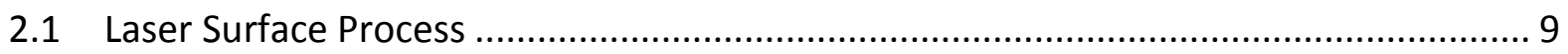

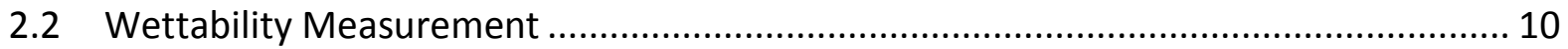

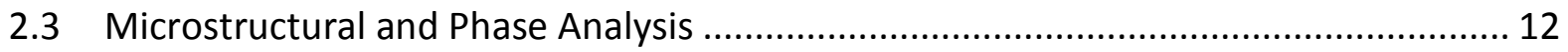

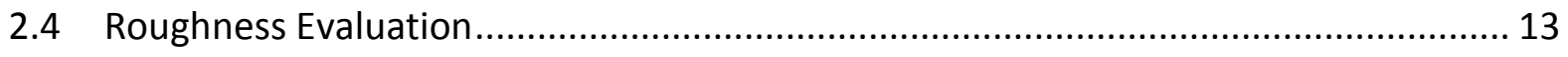

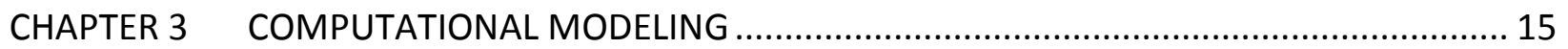

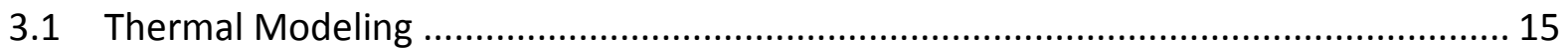

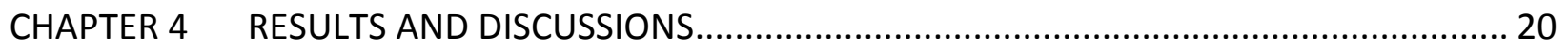

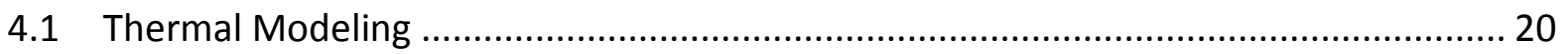

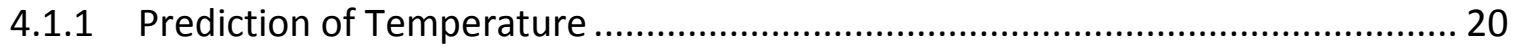

4.1.2 Cooling Rates/Solidification Rate Calculation .......................................... 21

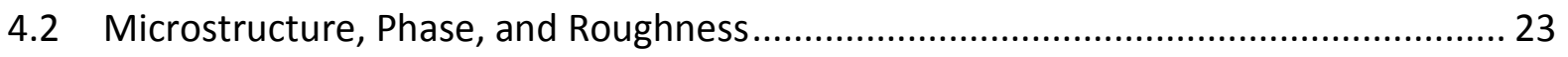




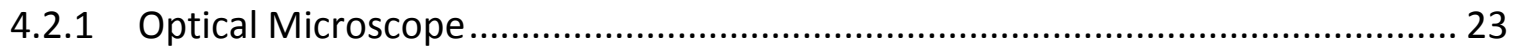

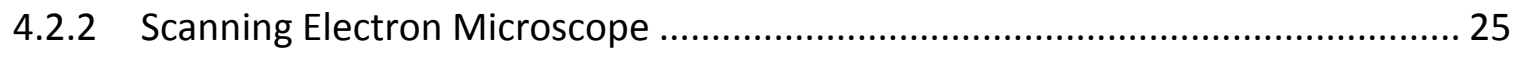

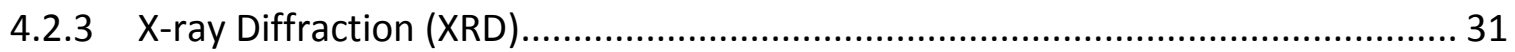

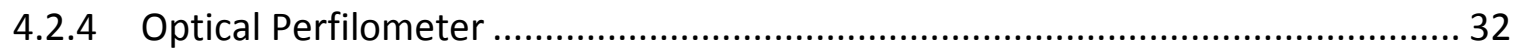

4.3 Effect of Surface Characteristics on Wettability............................................... 33

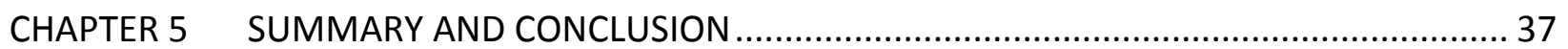

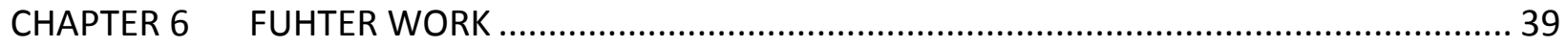

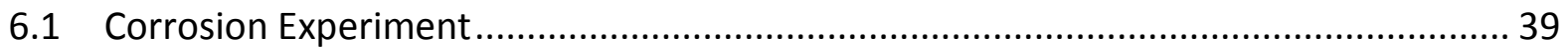

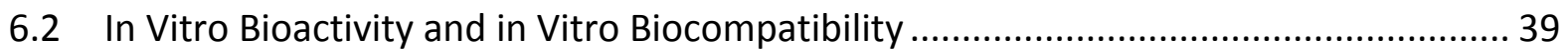

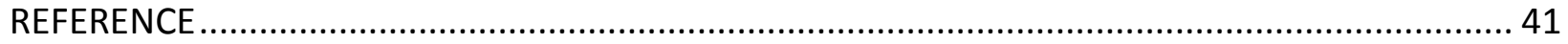




\section{LIST OF TABLES}

Page

Table 1.1 Mechanical properties comparing different metallic materials and human bone [6] ... 2

Table 2.1 Laser parameters for laser surface texturing..................................................... 10

Table 2.2 Surface energy components of the standard liquids (unit $\mathrm{mJm}^{-2}$ ) $[15,21] \ldots \ldots \ldots \ldots . . . .12$

Table 3.1 AZ31B Mg alloy thermal properties and modeling variables ................................. 17

Table 3.2 Boundary conditions for temperature changing calculations ................................ 18

Table 4.1 Cooling rates and solidification rates of all various laser energy density................... 23

Table 4.2 The optical microscopy images of varation laser energy density condition: (a) $1.06 \times 10^{6}$ $\mathrm{J} / \mathrm{m}^{2}$, (b) $2.12 \times 10^{6} \mathrm{~J} / \mathrm{m}^{2}$, (c) $3.18 \times 10^{6} \mathrm{~J} / \mathrm{m}^{2}$, (d) $4.24 \times 10^{6} \mathrm{~J} / \mathrm{m}^{2}$, and (e) $5.31 \times 10^{6} \mathrm{~J} / \mathrm{m}^{2} \ldots \ldots . .24$

Table 4.3 The results of surface roughness parameters of all laser process samples ............... 33

Table 4.4 Experimental results of contact angle of test liquids, surface energy components, and surface energy as function of sample processing conditions ...................................... 35

Table 4.5 The comparison of SBF contact angle, roughness parameter, surface energy, and surface average grain size of five laser process conditions ........................................ 36 


\section{LIST OF FIGURES}

Page

Figure 1.1. Schematic illustration of (a) contact angle formed by a liquid at the solid/liquid interface and the liquid/vapor interface, (b) a hydrophobic surface, and (c) hydrophilic

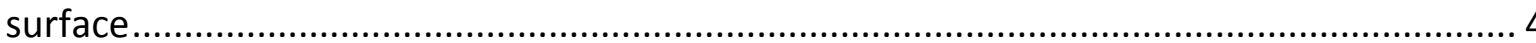

Figure 2.1 Illustration of laser surface texturing setup ..................................................... 9

Figure 2.2 Picture of CAM-Plus ${ }^{\circledR}$ contact angle goniometer (Reprint from source:http://www.chemsultants.com/testing-equipment-products/testing-

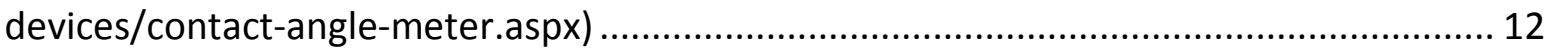

Figure 2.3 Picture of NANOVEA ${ }^{\circledR}$ PS50 3D optical profilometer (Reprinted from source: http://www.nanovea.com/Profilometers.html) 14

Figure 3.1 The geometry used in the computational model of laser surface process ................ 18

Figure 3.2 AZ31B Mg alloy density and thermal conductivity VS temperature [22-24]............ 19

Figure 4.1 Temperature profile for various laser energy density processing conditions............ 21

Figure 4.2 Schematic of crocess-section solidification of melt pool after laser process............. 23

Figure 4.3 Cross-section SEM images of laser surface process sample with $5.31 \times 10^{6} \mathrm{~J} / \mathrm{m}^{2}$ (a) low magnification of freezing region, (b) top region of $F Z$, (c) middle region of $F Z$, and (d)

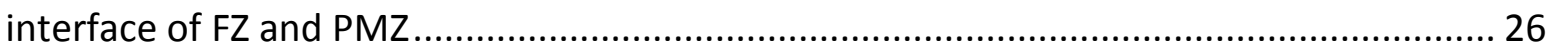

Figure 4.4 (a) SEM backscatter image and (b) EDS analysis results.................................... 27

Figure 4.5 Cross-section SEM images of all varation laser processing condition samples.......... 28

Figure 4.6 Cooling rate and grain size varation plot of all laser process conditions .................. 28 
Figure 4.7 (a) Temperatureprofile with solidification stages and (b) binary Mg-Al phase diagram

Figure 4.8 Denpendence of solidification structure on liquid temperature gradient and solidification rate

Figure 4.9 XRD pattern of as-received AZ31B Mg and all varation laser processing conditions sample

Figure 4.10 Three-dimensional surface morphology of as-received AZ31B and all varation laser surface modification sample. 33

Figure 4.11 The plots of surface energy, SBF contact angle, and roughness varation with different laser processing conditions. 36 


\section{CHAPTER 1}

\section{INTRODUCTION}

\subsection{Magnesium Metallic Bio-Implant}

Magnesium-based metallic biomaterials have become potential load-bearing implant materials and have attracted a great interest in the past decade [1-4]. Mg alloys exhibit several characteristics that make $\mathrm{Mg}$ a candidate biomaterial, such as being light-weight and light-

density (1.74 to $2.0 \mathrm{~g} / \mathrm{cm}^{3}$ ), similar elastic modulus (41 to $45 \mathrm{GPa}$ ) and to the compressive yield strength of natural bone [5-7]. In addition, $\mathrm{Mg}$ is essential to human metabolism and the fourth most abundant cation in the human body. The most important feature of $\mathrm{Mg}$ alloys for biomaterial science is their biodegradable property [7]. Magnesium can gradually be dissolved in the human body after implantation, the releasing of $\mathrm{Mg}^{+}$can be involved in metabolic reactions and biological mechanisms, and the soluble $\mathrm{Mg}$ oxide, which forms during corrosion, can be excreted by urine [8]. Until now there is no report on toxic reactions caused by an excess of $\mathrm{Mg}$ dissolved in the body [9]. Therefore Mg-based alloys are suitable to manufacture as wire, pine, plate, and screw implant for bone fracture fixation.

Comparing to the conventional metallic biomaterials such as Ti-6Al-4V, stainless steel, and Co-Cr based materials, using Mg implants can provide several benefits which other metallic implants lack. Table 1.1 shows the mechanical properties, comparing Mg with different metallic biomaterials and human bone. Because of its excellent mechanical properties, use of $\mathrm{Mg}$ implant will greatly reduce stress shielding of the bone and the associated loss of bone density [7]. In addition, since implants, that are metallic, not $\mathrm{Mg}$, are considered as a foreign organ to the human body, the long-term implantation of non-Mg materials cause local inflammation 
discomfort. Therefore, a second surgery is needed for implant removal [10]. However, repeated surgery increases the morbidity rate of patients, health care cost, and length for hospitalization. Hence high biocompatibility and the ability to degrade after bone regrowth are the significant reasons to develop $\mathrm{Mg}$ implants.

Table 1.1 Mechanical properties comparing different metallic materials and human bone [6]

\begin{tabular}{|c|c|c|c|c|c|}
\hline Property & Bone & $\begin{array}{l}\text { Magnesium } \\
\text { alloy }\end{array}$ & $\begin{array}{l}\text { Titanium } \\
\text { alloy }\end{array}$ & $\begin{array}{l}\mathrm{Co}-\mathrm{Cr} \\
\text { alloy }\end{array}$ & Stainless steel \\
\hline Density $\left(\mathrm{g} / \mathrm{cm}^{3}\right)$ & $1.8-2.1$ & $1.74-2.9$ & $4.4-4.5$ & $8.3-9.2$ & $7.9-8.1$ \\
\hline Elastic Modulus (GPa) & $3-20$ & $41-45$ & $110-117$ & 230 & $189-205$ \\
\hline $\begin{array}{l}\text { Compressive Strength } \\
\text { (Mpa) }\end{array}$ & $130-180$ & $65-100$ & 758-1117 & $450-1000$ & $170-310$ \\
\hline $\begin{array}{l}\text { Fracture Toughness } \\
\qquad\left(\mathrm{Mpa} / \mathrm{m}^{2}\right)\end{array}$ & $3-6$ & $15-40$ & $55-115$ & N/A & $50-200$ \\
\hline
\end{tabular}

However, the major limitation of $\mathrm{Mg}$ alloys is their inferior corrosion resistance property in biological fluid, especially in $\mathrm{Cl}^{-}$-containing environments $[7,9]$. The rapid corrosion causes lower cell activity and lower attachment due to the localized hydrogen gas produced during corrosion (8). Therefore, reducing the degradation rate in vivo is the first consideration for designing the Mg-based implant application. Among the many several series of $\mathrm{Mg}$ alloys, $\mathrm{AZ}$ series $\mathrm{Mg}$ alloys are some of the most widely used $\mathrm{Mg}$ alloys in industry. This type of alloy can exist for longer period in vivo environments due to $\beta-\mathrm{Mg}_{17} \mathrm{Al} \mathrm{I}_{12}$ intermetallic phase, which exhibits higher corrosion resistance than $\alpha-\mathrm{Mg}$ matrix $[11,12]$. The effectiveness of $\beta-\mathrm{Mg}_{17} \mathrm{Al}_{12}$ in corrosion resistance depends upon its concentration and distribution in matrix. If the $\beta$ $\mathrm{Mg}_{17} \mathrm{Al}_{12}$ exhibits a continuous network in the alloy, it will act as a barrier against corrosion [12]. 
Eventually, by varying the distribution, configuration and size of the $\beta-\mathrm{Mg}_{17} \mathrm{Al}_{12}$, the corrosion rate of the AZ31B Mg alloy can be changed.

\subsection{Wetting Effect of Bio-Application}

In general situations, biomaterials directly contact and interact with biological molecules, cells and tissues; these reaction processes all occur in biological fluids. Furthermore, surface wetting is the first and foremost phenomenon tat takes place when biomaterials are placed inside the body. Hence, surface wettability is considered as an important criterion that can dictate the biocompatibility of the implant. Biological reactions such as adsorption, platelet adhesion/activation, blood coagulation and cell and bacterial adhesion all take place on the implant surface and can be affected by surface wettability [13]. The surface wettability can be referred to as hydrophobicity and hydrophilicity, and it can be affected by surface roughness, chemical composition, and surface energy.

Contact angle measurements are the most common method for evaluating the surface wettability of the material [13-16]. There are five methods that can be carried out for contact angle measurement: (1) static, or sessile drop, (2) Wilhelmy plate, (3) captive air bubble, (4) capillary rise, and (5) tilted drop. Static, or sessile drop method is the most commonly used technique, because it is easy to conduct. In this case, a droplet is placed on the testing surface by using a contact angle goniometer. The contact angle is defined as an angle formed between the solid-liquid interface and the liquid-vapor interface and which has its vertex where the three interfaces meet as shown in Fig 1.1(a). Young's equation shows the relation of interfacial tensions of solid-vapor $\left(\nu_{\mathrm{sv}}\right)$, liquid-vapor $\left(\gamma_{\mathrm{Iv}}\right)$, solid-liquid $\left(\gamma_{\mathrm{s}}\right)$, and contact angle $(\theta)$ as follows: $\gamma_{l v} \cos \theta=\gamma_{s v}-\gamma_{s l}$ 
If the contact angle is greater than $90^{\circ}$, the surface can be considered as a hydrophobic surface

(Fig 1.1(b)). On the contrary, the small contact angle on the testing surface refers to the wetting or hydrophilic surface (Fig 1.1(c)).
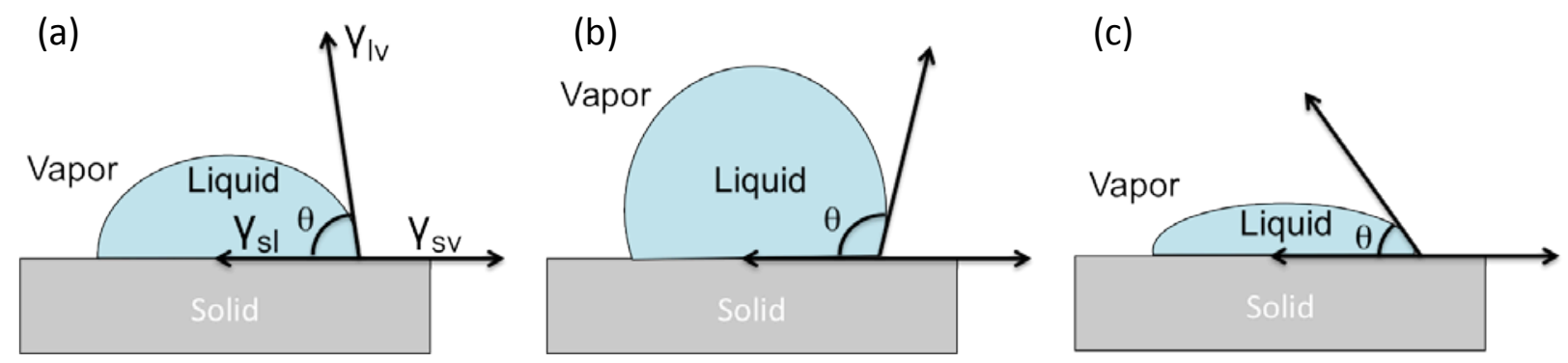

Figure 1.1. Schematic illustration of (a) contact angle formed by a liquid at the solid/liquid interface and the liquid/vapor interface, (b) a hydrophobic surface, and (c) hydrophilic surface

Although it has been broadly accepted that the biological response of the surface can be influenced by hydrophobicity/hydrophilicity, the wetting effects to cell behavior are still in controversy and inconsistency. Many researchers described that it is necessary to improve surface from hydrophobicity to hydrophilicity for supporting cell adherence and, in particular, growth. On the contrary, other researchers presented that the hydrophobic surface performed better cell response [13]. However, it is now well accepted in biomaterial community both overly hydrophobic and overly hydrophilic surface are not ideal for cell attachment, rather, surfaces with moderate wettability are able to absorb a proper amount of proteins, and at the same time preserve their natural conformation, resulting in positive cell response [17].

\subsection{Surface Modification Technique for Bio-Application}

Several phenomena occur on the material surface when it is placed into the living system. Within a few seconds during the initial implant stage, the proteins respond to the implant surface and form a thin layer of protein film on the surface. This reaction processing is 
important for bio-implants, because the protein film can absorb the living cell, then multiply and organize the various types of complex tissues. Therefore, the properties of the biomaterials' surface which play an important role and affect its interaction with proteins, can be characterized into 4 aspects [14]:

- Topography: More surface area of the implant can induce more interaction with proteins. Textures or three-dimensional topography such as grooves and pores obtain a great surface area than smooth surface.

- Chemical composition: The surface chemical composition determines the type of intermolecular forces governing the interaction with proteins.

- Heterogeneity: Metallic biomaterials usually exhibit grains with different phases and grain boundaries on the surface. The multiple domains interact with proteins differently in manner.

- Potential: Surface potential affects the distributions of ions surrounding the biomaterials and interacts with proteins.

Therefore, in order to improve protein absorption to the surface of bio-implants, surface engineering has become popular in biomaterials design. Surface modification techniques provide the ability to create the bioactivity and biocompatibility of materials in vivo through varying the surface properties while maintaining the bulk properties of the implant. Based on the different altered properties, surface modification technique can be classified into three:

- Morphological modification: The aim of morphological modification of biomaterial surface is to create three-dimensional features in the form of grating, pores, dots columns, pits, and random surface roughness. The purpose for creating these three- 
dimensional features is to imitate the extra-cellular matrix (ECM), a natural cell growth environment which obtains complicated nano and macrostructure. Several techniques have been used to achieve this type of surface modification such as ion beam etching, chemical etching, electron beam lithography, surface coating, mechanical roughening, and laser surface process.

- Physiochemical modification: The physiochemical characteristics such as surface energy, surface charge, and surface composition can be altered to effect biological responses of material. This can be achieved by various techniques such as grafting, surface coating, ion implantation, and glow discharge.

- Biological modification: This type of modification is used to design biomaterials equipped with molecular cues to imitate certain aspects of structure or function of natural extra-cellular microenvironments. Therefore biological modification techniques are used for controlling cell and tissue response to implant material. This can be achieved by immobilizing biomolecules representing such molecular cues on the surface of biomaterials. The common used biomolecules for immobilization include RGD peptides, heparin, and heparin sulfate binding peptides.

\subsubsection{Laser Surface Modification}

Laser surface engineering is a non-contact process, which has been used in many manufacturing industries such as aerospace, transportation, electronics, and medicine. It includes cladding, surface alloying, machining, and surface texturing, and so on. In laser surface modification high-density optical energy is incident on the surface of the processing material, and several phenomena take place on the surface which include melting, 
dissociation/decomposition, and evaporation to remove the material and produce 3 dimension surface feature. According to the particular material system and process parameters, laser processing on surface assists in verifying its microstructure, grain refinement, phase transformations, alloying and composite multiple phase without influencing the bulk properties.

The important thermal parameters of metal governing this technique are the specific heat, thermal conductivity, density, and latent heats of melting and evaporation. Furthermore, laser parameters such as power, scanning rate, and scanning spacing are also critical, and they need to be considered when processing surface modification. Not only do laser parameters create 3D surface feature, but they also affect the microstructure of the processing surface. For instance, laser power determines the maximum temperature attained and the cooling rate; and the duration of interaction which relates to the scanning rate, determines the reactions among phases; the scanning spacing determines the lateral track overlap, and so on. These kinds of changes in microstructure affect the mechanical properties, wear, and corrosion resistance significantly.

In the past decade, laser surface treatment has been used to study the effect of corrosion resistance, wear resistance, and mechanical properties of $\mathrm{Mg}$ biomaterials. Y.C. Guan et al. applied Nd:YAG laser to process surface melting on AZ91D Mg alloy. He described that after laser surface treatment, the refined continuous network of $\beta-\mathrm{Mg}_{17} \mathrm{Al} \mathrm{I}_{12}$ phases within the surface can play as the anticorrosion barriers. In a simulated body fluid immersion test, the treatment $\mathrm{Mg}$ alloy performed to higher corrosion resistance than the un-treatment $\mathrm{Mg}$ alloy [11]. X.D. Ming et al. used selective laser melting (SLM) to fabricate the pore shape structure 
surface of Mg bio-scaffold [18]. C.C Ng et al. investigated changing in the microstructure and mechanical properties of Mg alloy after LSM. He showed that with increasing laser energy density the size of equi-axed grain decreased, and the hardness of the laser-melting zone increased [19]. However, the co-relationship of surface roughness, surface chemical composition, and surface microstructure to surface wettability of Mg-Al-Zn alloy after laser surface texturing has not been investigated yet. Hence, in this study, the Nd:YAG laser system was used to generate variation texture surface on AZ31B Mg base alloy by different laser energy density. The purpose of this paper is to investigate the influence of laser energy density on surface wettability, microstructure, surface chemical composition, and surface roughness of AZ31B Mg for bio-implant application. 
CHAPTER 2

\section{EXPERIMENTAL PROCESS}

\subsection{Laser Surface Process}

The AZ31B Mg base alloy was used in this study with the following chemical composition (wt\%): Al 3.0, $\mathrm{Zn} \mathrm{1.0,} \mathrm{Mn} 0.5$ and $\mathrm{Mg}$ balance. The $\mathrm{Mg}$ rolled sheets were cut into $25 \mathrm{~mm} \times 25$ $\mathrm{mm} \times 7 \mathrm{~mm}$ by using a band saw. All the coupons were then polished from 320 grit to 1200 grit SiC paper, followed by rinsing with methanol. The polished coupons surface was scanned by using a 3 kW IPG CW diode-pumped ytterbium laser operated in the infrared region with wavelength of $1070 \mathrm{~nm}$. A fiber optic beam delivery cable interfaced with scan lab X-Y scanning mirrors were used to transfer the laser beam from laser system to the sprayed coupons. During laser scanning, coupon was placed in the container with glass cover, and then the Argon gas was inserted into the container to reduce the oxidation reaction. The schematic of the laser surface modification experimental setup is showed in Fig. 2.1, and the laser processing parameters used to create texture surface is listed in Table 2.1.

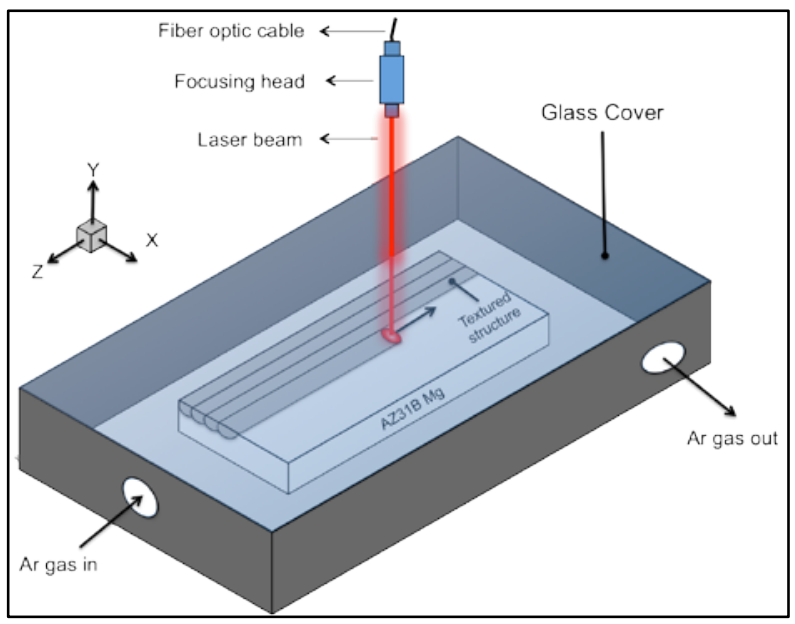

Figure 2.1 Illustration of laser surface texturing setup 
Table 2.1 Laser parameters for laser surface texturing

\begin{tabular}{ccc}
\hline Processing Parameters (units) & Symbol & Value \\
\hline Laser power $(\mathrm{W})$ & $\mathrm{P}$ & $250,500,750,1000,1250$ \\
Laser beam diameter $(\mathrm{mm})$ & $\mathrm{D}$ & 0.6 \\
Scanning speed $(\mathrm{mm} / \mathrm{s})$ & $\mathrm{S}$ & 500 \\
Fill spacing $(\mathrm{mm})$ & $\mathrm{FS}$ & 0.15 \\
Interaction time $(\mathrm{s}) \times 10^{-4}$ & $\mathrm{t}_{\mathrm{r}}=\mathrm{D} / \mathrm{S}$ & 0.0012 \\
Energy density $\left(\mathrm{J} / \mathrm{m}^{2}\right) \times 10^{6}$ & $\mathrm{E}_{\mathrm{g}}=\left\{\mathrm{P} /\left(\frac{\pi}{4} \mathrm{D}^{2}\right)\right\} \times \mathrm{t}_{\mathrm{r}}$ & $1.06,2.12,3.18,4.24,5.31$ \\
\hline
\end{tabular}

\subsection{Wettability Measurement}

The surface wettability evaluation was carried out by a static sessile drop technique (contact angle measurement) by using CAM-Plus ${ }^{R}$ contact angle goniometer (Cheminstruments, Inc. Fairfiled, $\mathrm{OH}$ ), equipped with a fiber optic light source as shown in Fig 2.2. A liquid droplet of volume $3 \mu \mathrm{l}$ (droplet diameter of $2 \mathrm{~mm}$ ) was placed on the thoroughly cleaned surface by a hypodermic syringe. The liquid droplet was placed on the surface for approximately $10 \mathrm{~s}$ to stabilize before the reading was taken. The measurement was carried out at room temperature $\left(25^{\circ} \mathrm{C}\right)$ and a minimum of ten contact angle readings were taken on each testing surface to minimize errors in the measurement. In order to eliminate the error associated with the arbitrary tangential alignment, the contact angle was measured based on the patented half angle method (US Patent 5268 733).

According to the Van Oss [20] approach, the surface energy can be calculated by the following equation:

$$
(1+\cos \theta) \gamma_{L}=2\left\{\left(\gamma_{S}^{L W} \gamma_{L}^{L W}\right)^{1 / 2}+\left(\gamma_{S}^{+} \gamma_{L}^{-}\right)^{1 / 2}+\left(\gamma_{S}^{-} \gamma_{L}^{+}\right)^{1 / 2}\right\}
$$


In this approach the $\gamma$ is the surface energy, surface energy can be divided into the Lifshitz van der waals surface energy $\left(\gamma^{L W}\right)$ and Lewis acid-base surface energy $\left(\gamma^{A B}\right)$ components as in the following equation:

$\gamma=\gamma^{L W}+\gamma^{A B}$

$\gamma^{A B}=2 \sqrt{\gamma^{+} \gamma^{-}}$

Here $\gamma^{+}$is the Lewis acidic or the electron-acceptor component, $\gamma^{-}$is the Lewis basic or the electron-donor component, $\theta$ is the contact angle of liquid and solid, a subscript $\mathrm{S}$ is the solid, and subscript $L$ is the liquid. To solve three unknown components, $\gamma_{S}^{L W}, \gamma_{S}^{+}$and $\gamma_{S}^{-}$, in Eq. (1), there were needed three well-characterized test liquids for calculation. One polar (1Bromonaphthalene) and two polar liquids (water and Formamide) were used in the test, and their surface energy is listed in Table 2.2. In order to correlate the surface energy calculation to bio-wettability of the sample, contact angle measurement was also performed for simulated body fluid (SBF) solution. The chemical compositions of SBF are in the following order: $\mathrm{NaCl}$ (8.026 g), $\mathrm{NaHCO}_{3}(0.352 \mathrm{~g}), \mathrm{KCL}(0.225 \mathrm{~g}), \mathrm{K}_{2} \mathrm{HPO}_{4} \bullet 3 \mathrm{H}_{2} \mathrm{O}(0.230 \mathrm{~g}), \mathrm{MgCl}_{2} \bullet 6 \mathrm{H}_{2} \mathrm{O}(0.311 \mathrm{~g}), \mathrm{CaCl}_{2}$ $(0.293 \mathrm{~g})$ and $\mathrm{Na}_{2} \mathrm{SO}_{4}(0.072 \mathrm{~g})$ into D.I water $(700 \mathrm{ml})$. 


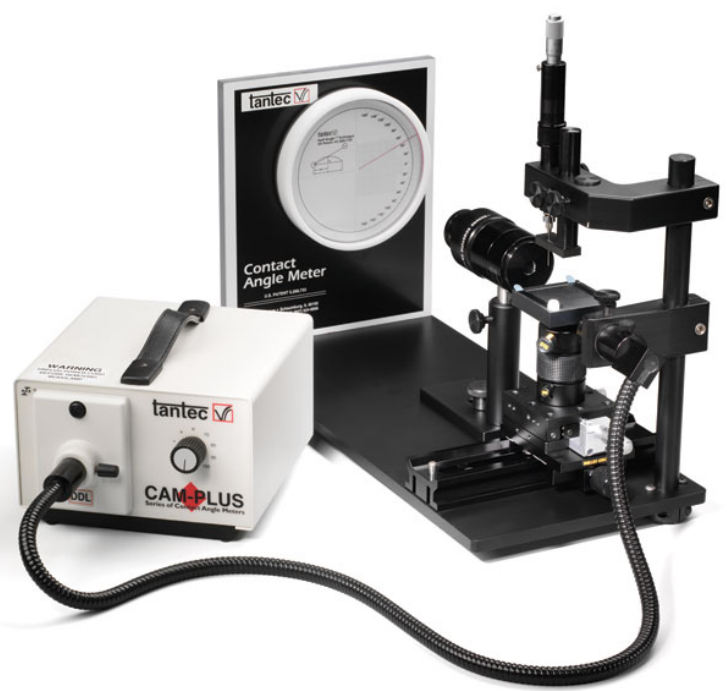

Figure 2.2 Picture of CAM-Plus ${ }^{\circledR}$ contact angle goniometer (Reprint from source:http://www.chemsultants.com/testing-equipment-products/testing-devices/contactangle-meter.aspx)

Table 2.2 Surface energy components of the standard liquids (unit $\mathrm{mJm}^{-2}$ ) $[15,21]$

\begin{tabular}{ccccc}
\hline Liquid & $\boldsymbol{\gamma}$ & $\boldsymbol{\gamma}^{\mathrm{LW}}$ & $\boldsymbol{\gamma}^{+}$ & $\boldsymbol{\gamma}^{-}$ \\
\hline 1-Bromonaphthalen & 44.4 & 44.4 & 0 & 0 \\
Water & 72.8 & 21.8 & 25.5 & 25.5 \\
Formamide & 58.0 & 39.0 & 2.28 & 39.6 \\
\hline
\end{tabular}

\subsection{Microstructural and Phase Analysis}

For the microstructural observation in the cross-section of laser-processed coupons, the coupons were initially sectioned perpendicular to the laser track by using a low speed diamond saw. The sectioned coupons were then polished with SiC paper from 400 grit to 1200 grit, followed by disk polishing with $\mathrm{Al}_{2} \mathrm{O}_{3}$ powder of $1 \mu \mathrm{m}, 0.5 \mu \mathrm{m}$, and $0.05 \mu \mathrm{m}$ to get a mirrorfinished surface. Then the polished coupons were cleaned by ultrasonic with methanol and etched with the etchant constituting of a mixture of $5 \mathrm{~mL}$ acetic acid, 6 g picric acid, $10 \mathrm{~mL} \mathrm{H}_{2} \mathrm{O}$ 
and $100 \mathrm{~mL}$ ethanol (95\%) for approximately $10 \mathrm{~s}$ by putting etching drop on the polished surface to reveal the microstructure features. The microstructural analysis was carried out by a FEI Quanta 200 environmental scanning electron microscope (ESEM).

Phase identification in the laser textured coupons and the untreated $\mathrm{Mg}$ alloy were studied by using a Rigaku III X-ray diffractometer (XRD) with $\mathrm{Cu} \mathrm{K} \alpha$ radiation of wavelength $0.15418 \mathrm{~nm}$. The XRD system was operated at $40 \mathrm{kv}$ and $44 \mathrm{~mA}$ in a $2 \theta$ range of $20^{\circ}-90^{\circ}$ using a step size of $0.025^{\circ}$ and a scan rate of $4^{\circ} / \mathrm{min}$. The standard software (JADE) was used for background correction, and the phases present were identified by comparing the XRD pattern with standard ICDD (International Center for Diffraction Data) files obtained from the joint committee of powder diffraction standards (JCPDS).

\subsection{Roughness Evaluation}

The surface roughness of the laser textured coupons was measured by NANOVEA ${ }^{\circledR}$ PS50 optical perfilometer (Fig. 2.3) with an optical pen of $400 \mu \mathrm{m}$ at scanning rate of $1 \mu \mathrm{m} / \mathrm{s}$. The laser beam across a surface area of $10 \mathrm{~mm} \times 10 \mathrm{~mm}$. The surface profile measurement process followed the standard protocol which is given by the ISO 251782:2012 (Geometric Product Specifications-Surface texture: areal) specifications. The raw data recorded previously during the surface profile measurements was further post-processed by using the NANOVEA ${ }^{\circledR}$ 3D software based on the standard inbuilt NANOVEA ${ }^{\circledR}$ template. Eventually, area-profile measurements were carried out to measure the roughness parameters in the form of $S_{a}$ (arithmetic mean height, $\mu \mathrm{m}$ ) and $\mathrm{S}_{\mathrm{q}}$ (root mean square height, $\mu \mathrm{m}$ ). 


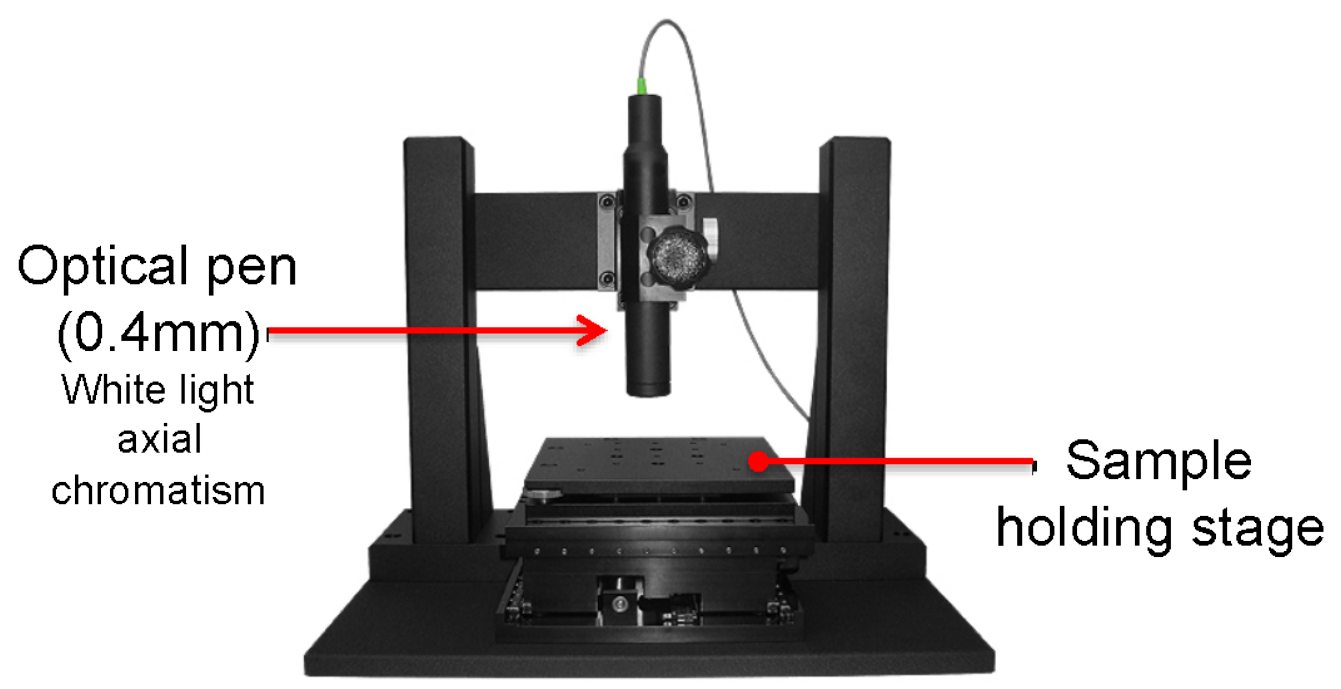

Figure 2.3 Picture of NANOVEA ${ }^{\circledR}$ PS50 3D optical profilometer (Reprinted from source: http://www.nanovea.com/Profilometers.html) 


\section{CHAPTER 3}

\section{COMPUTATIONAL MODELING}

\subsection{Thermal Modeling}

COMSOL Multiphysics is a finite element-modeling program, which can provide a simulation environment to illustrate the physics-based phenomena. In this thesis, associated with the laser surface texturing process COMSOL was used to simulate both the surface temperature changing and the melting depth calculation.

During the laser surface process, while the laser beam was incident on the sample surface, some part of the laser energy was lost because of material reflection and glass absorption, and then the remaining amount of energy was absorbed by the material. The absorbed laser energy caused several phenomena on the surface such as heating, melting, and vaporization. Therefore, the varying laser-processing parameters and thermo-physical properties of the material play an important effect regarding these phenomena. The material thermal properties and variables used in the computation model are listed in Table 3.1. In order to estimate the absorptivity $(A)$ in table 3.1, optical microscopy was carried out to measure the depth of melt pool, then the results were used to compare the computational predicted and to find the actual glass absorption. Furthermore, the thermal-physical properties such as temperature profile and depth of surface melting were affected by phase change. Hence, the temperature dependent material property for the density and specific heat was also incorporated in the heat transfer model which is expressed by $\rho$ and $\mathrm{Cp}$ in the Table 3.1. In order to increase the computation rate and reduce the cost, the transient two-dimensional axis-symmetric cutting plane $\mathrm{XY}$ was designed as shown in Fig. 3.1. The governing equation for 
two-dimensional heat transfer in Cartesian coordinates is given by Eq. (1) of Table 3.2. Another governing factor for this model is the different assigning boundary conditions that in turn combine different heat transfer phenomena. The Boundary \#6 shown in Fig. 3.1 is assigned by the three boundary conditions: heat flux, convection, and surface-to-ambient radiation that are expressed by the Eq. (2) of Table 3.2. Eq. (3) of Table 3.2 expresses that the laser-power distribution used in the model is Gaussian. Boundaries \#1, 3, 6, 8, and 9, shown in Fig. 3.1, were subjected to natural convective cooling and surface-to ambient conditions. Eq. (4) and (5) in Table 3.2 are used to represent the boundary conditions for boundary combination \#1 and 9, and 3 and 8 respectively. Furthermore, Boundary \#2 was assumed that it is not involved in any of the heat-transfer modes. Therefore, It is subjected to an insulated boundary as expressed by Eq. (6) of Table 3.2. In order to confirm the modeling results, the computationally predicted depth of melting will be compared to the experimentally measurement via optical microscopy. 
Table 3.1 AZ31B Mg alloy thermal properties and modeling variables

\begin{tabular}{|c|c|c|}
\hline Material Properties (units) & Symbol & Value \\
\hline Density $\left(\mathrm{kg} / \mathrm{m}^{3}\right)$ & $\rho$ & See Fig. 3.2 [22] \\
\hline Heat capacity (J/kg.K) & $\mathrm{Cp}$ & $\begin{array}{l}896+\delta . \Delta \mathrm{H}+\left(\frac{\Delta \mathrm{H}}{\mathrm{T}_{\mathrm{m}}}\right) * \mathrm{H}^{\prime}\left(\left(\mathrm{T}-\mathrm{T}_{\mathrm{m}}\right), \Delta \mathrm{T}\right) \\
\text { where, } \delta=\exp \left[-\left(\frac{\left(\mathrm{T}-\mathrm{T}_{\mathrm{m}}\right)^{2}}{\Delta \mathrm{T}^{2}}\right)\right] / \Delta \mathrm{T} \sqrt{\pi}\end{array}$ \\
\hline Thermal conductivity (W/m.K) & $\mathrm{K}$ & See Fig. $3.2[23,24]$ \\
\hline Melting Temperature (K) & $T_{m}$ & 1940 \\
\hline Latent heat of melting $(\mathrm{J} / \mathrm{g})$ & $\Delta \mathrm{H}$ & 340 \\
\hline Melting range $(\mathrm{K})$ & $\Delta \mathrm{T}$ & 10 \\
\hline Modeling Variables (units) & Symbol & Value \\
\hline Absorptivity & $A$ & 0.158 \\
\hline Heat transfer coefficient $\left(\mathrm{W} / \mathrm{m}^{2} . \mathrm{K}\right)$ & $\mathrm{h}$ & 10 \\
\hline Emissivity & $\varepsilon$ & 0.070 \\
\hline $\begin{array}{c}\text { Reference point to represents center of } \\
\text { the laser beam }(\mathrm{mm})\end{array}$ & $X_{r}$ & 2.5 \\
\hline $\begin{array}{c}\text { Standard deviation of the Gaussian laser } \\
\text { beam }\end{array}$ & $\phi$ & 0.15 \\
\hline Initial temperature $(\mathrm{K})$ & $\mathrm{T}_{\mathrm{i}}$ & 298.15 \\
\hline Stefan-Bolzmann constant & $\sigma$ & $5.67 \times 10^{-8}$ \\
\hline
\end{tabular}


Table 3.2 Boundary conditions for temperature changing calculations

\begin{tabular}{|c|c|c|c|}
\hline Boundary\# & $\begin{array}{l}\text { Boundary condition } \\
\text { [Reference] }\end{array}$ & Equation & $\begin{array}{c}\text { Eq. } \\
\#\end{array}$ \\
\hline $\begin{array}{l}\text { Whole } \\
\text { geometry }\end{array}$ & Governing equation & $\rho c_{p}\left[\frac{\partial \mathrm{T}}{\partial \mathrm{t}}\right]=\mathrm{k}\left[\left(\frac{\partial^{2} \mathrm{~T}}{\partial \mathrm{x}^{2}}\right)+\left(\frac{\partial^{2} \mathrm{~T}}{\partial \mathrm{y}^{2}}\right)\right]$ & (1) \\
\hline \multirow[t]{2}{*}{6} & $\begin{array}{l}\text { Heat flux, natural } \\
\text { convection cooling and } \\
\text { radiation }\end{array}$ & $\begin{array}{c}-\mathrm{k} \frac{\partial \mathrm{T}}{\partial \mathrm{y}}=\varphi \mathrm{P}_{\mathrm{g}}-\mathrm{h}\left[\mathrm{T}-\mathrm{T}_{\mathrm{i}}\right]-\varepsilon \sigma\left[\mathrm{T}^{4}-\mathrm{T}_{\mathrm{i}}^{4}\right] \\
\text { where, } \varphi=1 \text { for } 0 \leq \mathrm{t} \leq \mathrm{t}_{\mathrm{r}} \text {, and } \varphi=0 \text { for } \mathrm{t} \\
\geq \mathrm{t}_{\mathrm{r}}\end{array}$ & (2) \\
\hline & $\begin{array}{l}\text { Average laser power } \\
\text { density in Gaussian } \\
\text { distribution }\end{array}$ & $P_{g}=A\left[\frac{P}{\left(\frac{\pi}{4} D^{2}\right)}\right] \cdot \exp \left[-\left(\frac{\left(x-x_{r}\right)^{2}}{2 \emptyset^{2}}\right)\right]$ & (3) \\
\hline 1,9 & $\begin{array}{c}\text { Natural convection cooling } \\
\text { and radiation }\end{array}$ & $-\mathrm{k} \frac{\partial \mathrm{T}}{\partial \mathrm{x}}=\mathrm{h}\left[\mathrm{T}-\mathrm{T}_{\mathrm{i}}\right]-\varepsilon \sigma\left[\mathrm{T}^{4}-\mathrm{T}_{\mathrm{i}}^{4}\right]$ & (4) \\
\hline 3,8 & $\begin{array}{l}\text { Natural convection cooling } \\
\text { and radiation }\end{array}$ & $-\mathrm{k} \frac{\partial \mathrm{T}}{\partial \mathrm{y}}=\mathrm{h}\left[\mathrm{T}-\mathrm{T}_{\mathrm{i}}\right]-\varepsilon \sigma\left[\mathrm{T}^{4}-\mathrm{T}_{\mathrm{i}}^{4}\right]$ & (5) \\
\hline 2 & Insulation & $\frac{\partial \mathrm{T}}{\partial \mathrm{y}}=0$ & (6) \\
\hline $4,5,7$ & Neutral & - & \\
\hline
\end{tabular}

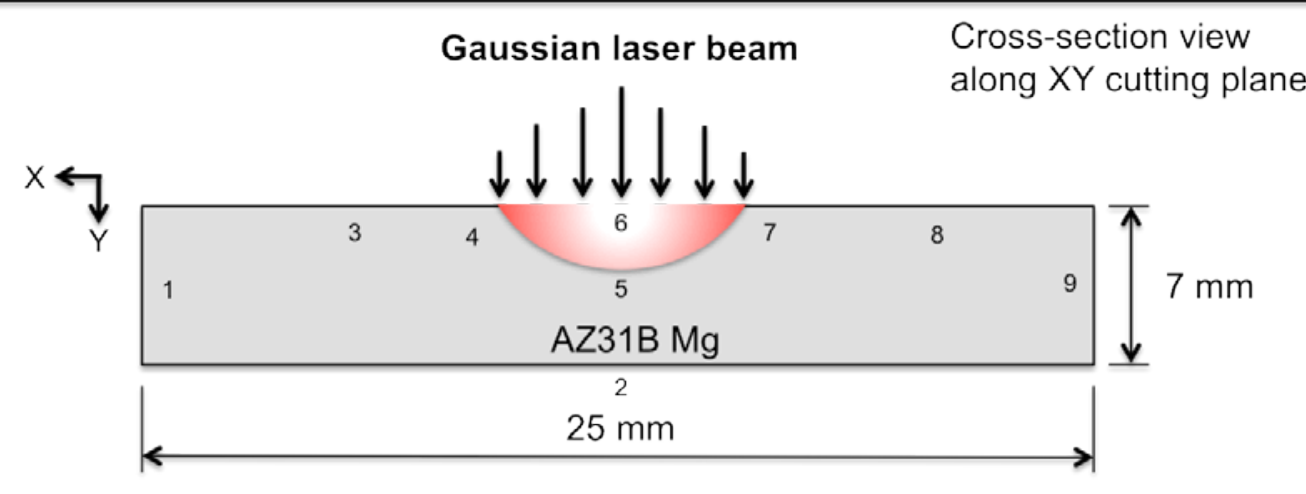

Boundary Conditions for thermal modeling

Figure 3.1 The geometry used in the computational model of laser surface process 


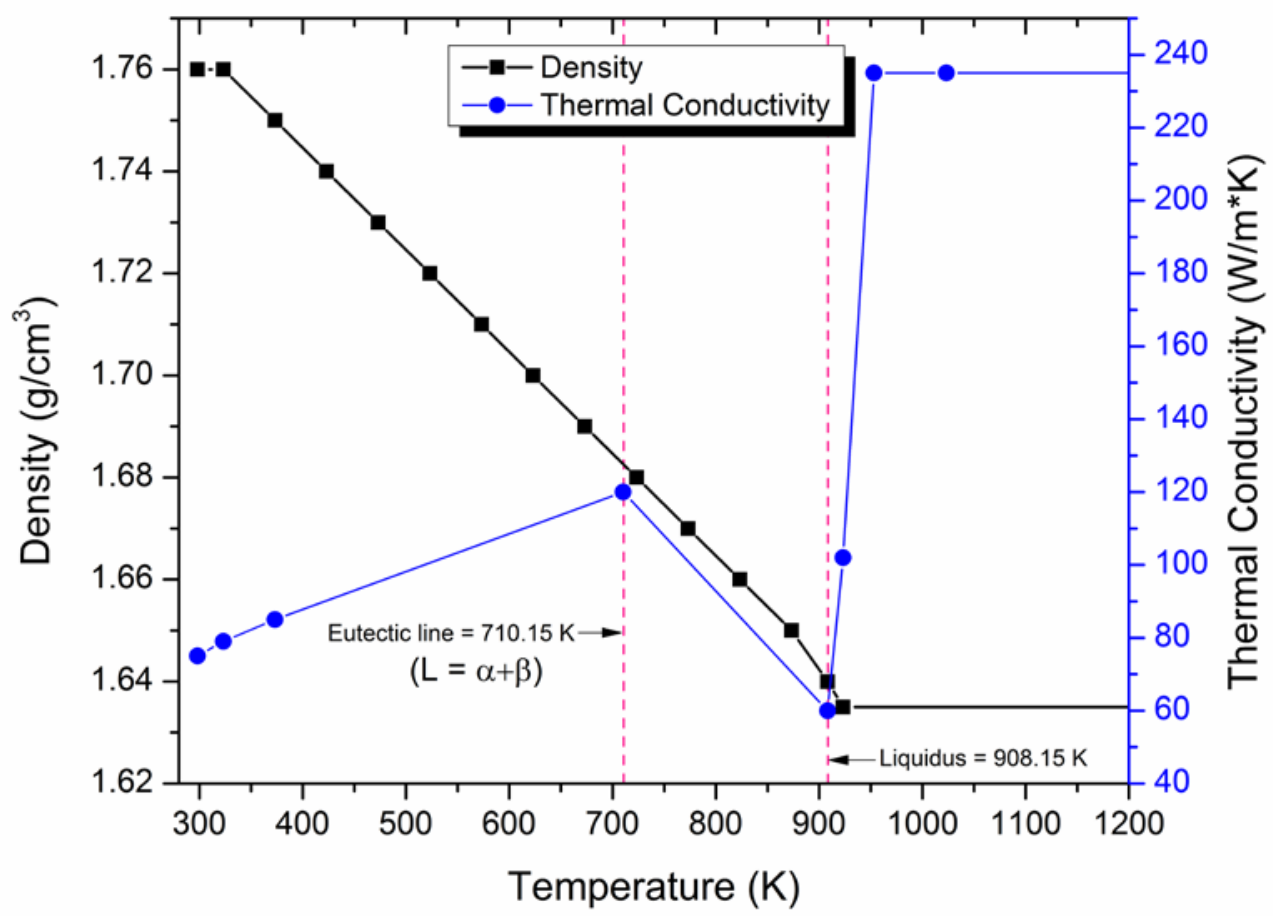

Figure 3.2 AZ31B Mg alloy density and thermal conductivity VS temperature [22-24] 
CHAPTER 4

\section{RESULTS AND DISCUSSIONS}

\subsection{Thermal Modeling}

\subsubsection{Prediction of Temperature}

Base on the Boundary conditions and the whole geometry, the variation temperature profile for all laser processing parameters $\left(1.06 \times 10^{6} \sim 5.31 \times 10^{6} \mathrm{~J} / \mathrm{m}^{2}\right)$ were evaluated and presented in Fig. 4.1. During the laser processing, the temperature of the laser-surface interaction zone rose and fell rapidly due to the localized nature of the laser beam. In the meanwhile, several different physical phenomena took place in the material, such as rapid heating by the incident laser, self-quenching by the bulk mass material, and heat losses by external natural convection and radiation. The laser surface modification was carried out with five different laser powers ( $P=250 \mathrm{~W}, 500 \mathrm{~W}, 750 \mathrm{~W}, 1000 \mathrm{~W}, 1250 \mathrm{~W})$, and their corresponding laser energy density are calculated and listed in Table 2.1. Laser energy density increases with increasing laser powder. For $1.06 \times 10^{6} \mathrm{~J} / \mathrm{m}^{2}$ laser processing condition, the laser power is the lowest $(250 \mathrm{~W})$, as compared to other laser processing powers. In Fig. 4.1 the temperature profile shows that the maximum temperature of all laser processing conditions was higher than the liquid phase temperature of AZ31B (903K). Therefore the melt pool will grow within the interaction zone. However, only a shallow depth of material was affected by that temperature due to the short resident time $(1.2 \mathrm{~ms})$. With increased laser energy density the size of the melt pool became greater, and once this size is known, them the depth of the melt pool can be predicted. During heating and cooling cycles, the material surface experienced the phase 
change. In temperature profile (Fig. 4.1) the heat consumed and heat released, which are affected by phase change can be observed by the plateau near the melting temperature (903K).

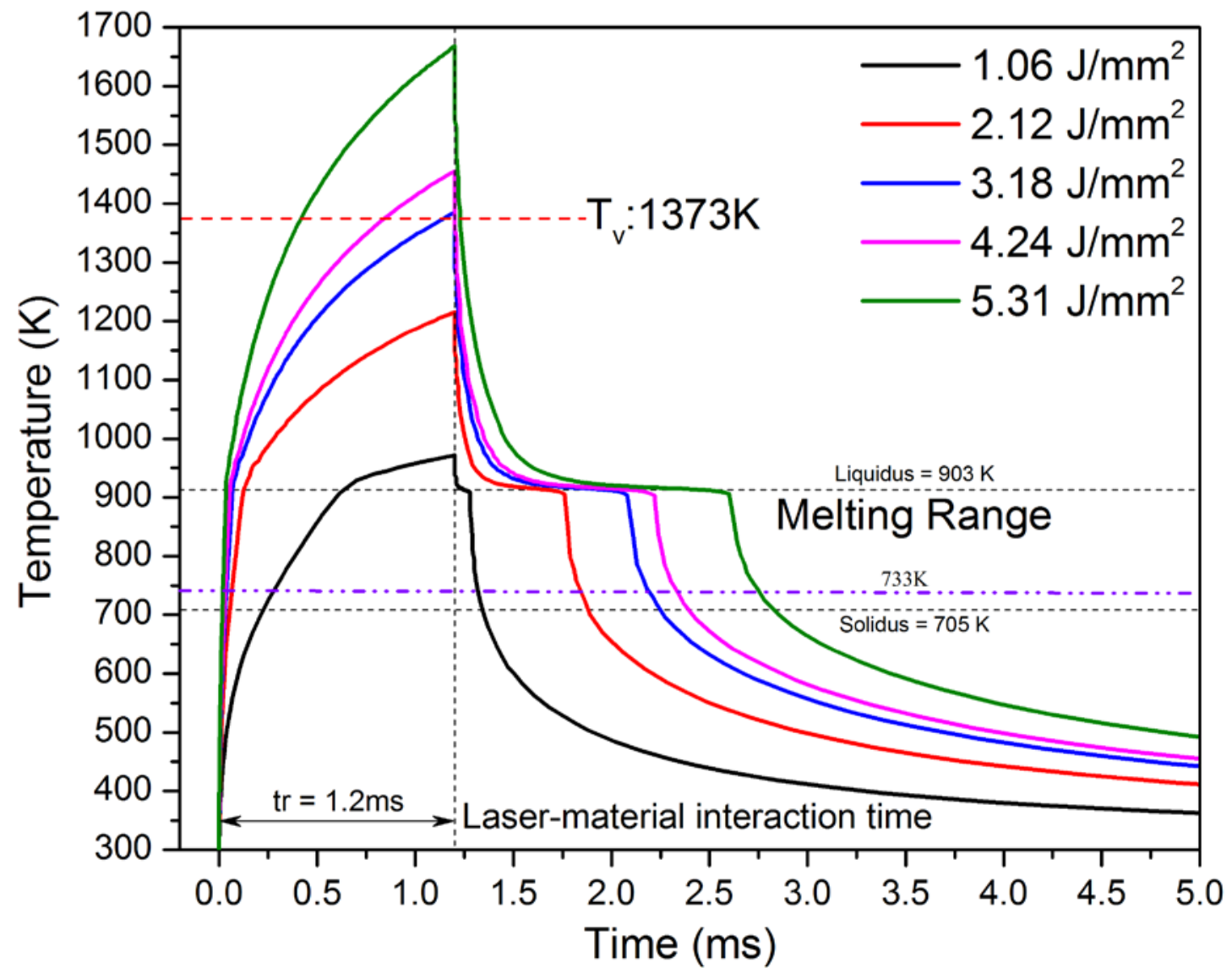

Figure 4.1 Temperature profile for various laser energy density processing conditions

\subsubsection{Cooling Rates/Solidification Rate Calculation}

From the temperature profile for various laser energy density conditions (Fig. 4.1), corresponding cooling rates and solidification rates were calculated. The cooling rate and solidification rate equations are listed by the following:

Cooling rate $=\frac{d T}{d t}\left(\frac{K}{s}\right)$

Solidification rate $=\frac{\text { Cooling rate }(d T / d s, K / \mathrm{s})}{\text { Temperature gradient }(d T / d x \text { or } d y, K / \mathrm{mm})}\left(\frac{\mathrm{mm}}{\mathrm{s}}\right)$ 
To understand the physical effect of the cooling rate and solidification rate, the schematic cross-section of laser-materials interaction zone is shown in Fig. 4.2. Due to the material radiation and convective cooling, the substrate around the melt pool plays a role as a heat sink and subsequently decreases temperature in a very short time after the laser beam is removed. Since the solidification initial at the solid-liquid interface, the solidification rate can be considered as the velocity of the interface moving forward to the top center of the melt pool. Furthermore, the processing zone experiences grain refinement due to the rapidly heating and cooling process. Thus it is important to understand the history of the microstructure by evaluating the temperature gradient along the $\mathrm{X}$ - and $\mathrm{Y}$-axis during solidification. During laser $\mathrm{ON}$ in resident time (tr) the temperature of the laser-material interaction zone first rises up, and the melt pool starts to grow when the temperature reaches eutectic temperature $(705 \mathrm{~K})$ within a short time $(<0.5 \mathrm{~ms})$. With temperature increasing, the melt pool keeps growing into the solid until the temperature reaches maximum. For the processing condition of highest laser energy density $\left(5.31 \times 10^{6} \mathrm{~J} / \mathrm{m}^{2}\right)$, the final temperature peak is the highest as compare to the other processing conditions. During solidification (change from liquid phase to solid phase), the temperature first decreased quickly from liquid line (903K) to the room temperature, and, as a result, the cooling rate dropped rapidly due to self-quenching and heat losses by the external natural convection and radiation. The computed cooling rates and solidification rates of all processing conditions are listed in Table 4.1. All five processing conditions show the high cooling rates, which indicate the rapid solidification. Furthermore, the solidification rate along $\mathrm{Y}$-axis is higher than along $\mathrm{X}$-axis, and these results will be approved by the microstructure. 


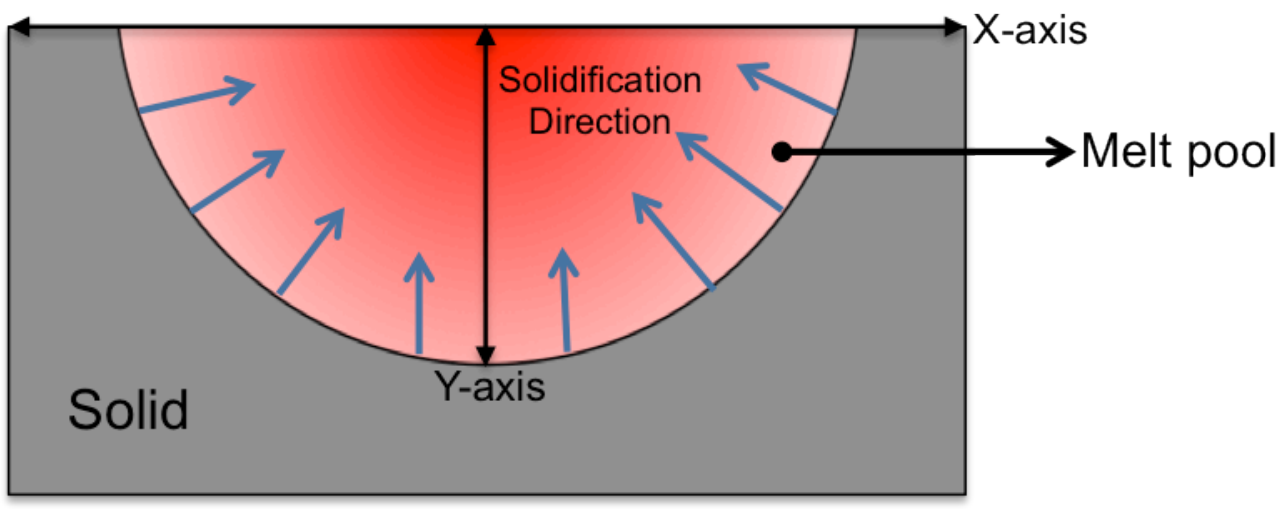

Figure 4.2 Schematic of crocess-section solidification of melt pool after laser process

Table 4.1 Cooling rates and solidification rates of all various laser energy density

\begin{tabular}{cccc}
\hline $\begin{array}{c}\text { Laser Processing } \\
\text { Condition }\left(\times 10^{6} \mathrm{~J} / \mathrm{m}^{2}\right)\end{array}$ & Cooling rates $(\mathrm{K} / \mathrm{s})$ & $\begin{array}{c}\text { Solidification rates } \\
\text { along Y-axis }(\mathrm{mm} / \mathrm{s})\end{array}$ & $\begin{array}{c}\text { Solidification rates } \\
\text { along X-axis }(\mathrm{mm} / \mathrm{s})\end{array}$ \\
\hline 1.06 & $0.72 \times 10^{4}$ & 2.35 & 1.66 \\
2.12 & $1.01 \times 10^{4}$ & 3.11 & 2.29 \\
3.18 & $1.36 \times 10^{4}$ & 3.15 & 2.61 \\
4.24 & $1.61 \times 10^{4}$ & 3.34 & 2.69 \\
5.31 & $2.07 \times 10^{4}$ & 3.7 & 2.95 \\
\hline
\end{tabular}

\subsection{Microstructure, Phase, and Roughness}

\subsubsection{Optical Microscope}

To confirm the computational prediction of the depth of melt, the experimental measurement was carried out by the optical microscopy. The optical images and the depth of melt of all various laser energy density conditions are listed in Table 4.2. It clearly shows a distinguished different in color brightness between the freezing region and the substrate in the optical images. The freezing region exhibits darker color and needle-like structure, and the substrate exhibits a bright contrast. Due to the multiple laser scanning process, within the freezing region several overlay boundaries can be observed. The results of the depth of melt measurement of various laser processing conditions (Table 4.2) confirms that by increasing the 
laser energy density, more material was transferred into liquid phase and then reformed as new microstructure. In order to find out the actual glass absorption, Furthermore, the measurement results were used to compare to computational predict, then the absorptivity was adject until the difference between the measurement results and computational predict reduce to minimum value.

Table 4.2 The optical microscopy images of varation laser energy density condition: (a) $1.06 \times 10^{6}$ $\mathrm{J} / \mathrm{m}^{2}$, (b) $2.12 \times 10^{6} \mathrm{~J} / \mathrm{m}^{2}$, (c) $3.18 \times 10^{6} \mathrm{~J} / \mathrm{m}^{2}$, (d) $4.24 \times 10^{6} \mathrm{~J} / \mathrm{m}^{2}$, and (e) $5.31 \times 10^{6} \mathrm{~J} / \mathrm{m}^{2}$

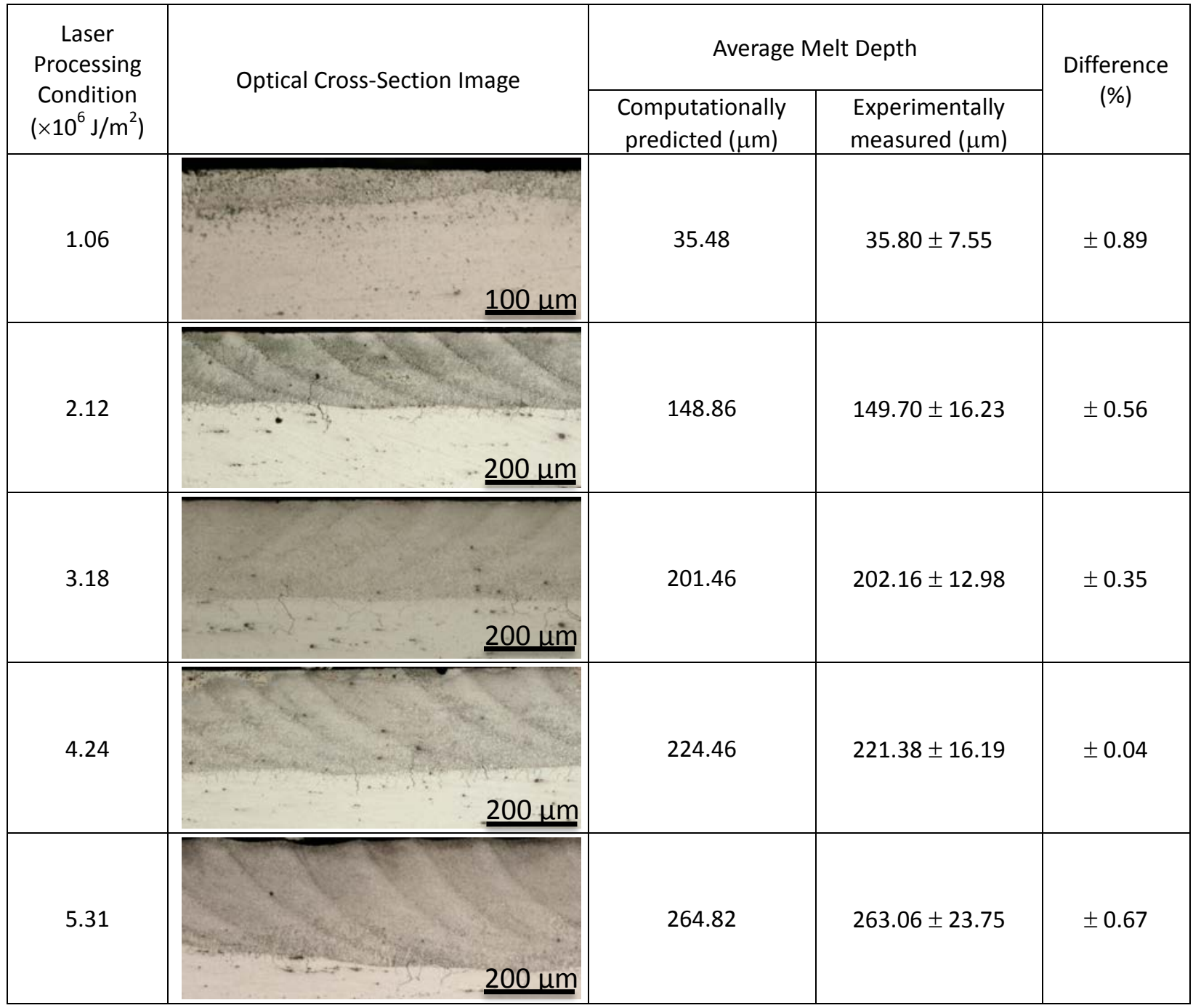




\subsubsection{Scanning Electron Microscope}

Low magnification cross-section SEM (Fig. 4.3(a)) of the laser surface processing sample clearly shows the effect of laser energy density on the microstructure within the freezing region. The laser surface processing resulted in three distinct structures in freezing region, namely, two in the fusion zone (FZ) and one in the partial melting zone (PMZ). The cross-section SEM secondary electron micrograph displayed the clearly different features between microstructures. Within the FZ existed two different microstructures: equi-axed and columnar. Fig. 4.3(a) shows the equi-axed structure distributed uniformly in the top area of $F Z$, and the columnar structure grown perpendicular from the laser track overlay boundary which was produced by the multiple laser scanning processing on the surface. Fig. 4.3(b) shows the high magnification of the equi-axed structure. It indicates that during the solidification, the temperature gradient of that region was uniform. Fig. 4.3(c) displays the high magnification of the columnar structure, which indicates that the temperature gradient of that region was greater along the Y-axis. Fig. 4.3(d) displays both the columnar structure, which grew from the fusion zone-ZPM boundary, and the narrow bands around the FZ. Furthermore, in Fig. 4.3(b), (c), and (d) the cores are distributed uniformly within the columnar grains. To identify the phases of the microstructure in the fusion zone, SEM backscatter electron micrographs of the fusion zone (Fig. 4.4(a)) revealed the composition variation at grains, grain boundaries, and cores. The matrix grains exhibit a darker contrast, and grain boundaries and cores show a brighter contrast. This face indicates that the boundary of the equi-axed, columnar, and cored obtain more Al contain than grains. Fig. 4.4(b) exhibits the results of EDS analysis that further confirm the chemical composition of grain, grain boundary, and core. Within the grains, EDS 
signal resulted only in a single Mg peak, and at the grain boundary and core, the signals showed both $\mathrm{Mg}$ and $\mathrm{Al}$ peaks. These results indicate that after laser process $\beta-\mathrm{Mg}_{17} \mathrm{Al}_{12}$ has high possibility to grow in grain boundaries and cores. However, due to the rapidly cooling rate, $\beta$ $\mathrm{Mg}_{17} \mathrm{Al}_{12}$ can only grow as fine precipitates with few nanometers. Thus it is hard to observe and quantify $\beta-\mathrm{Mg}_{17} \mathrm{Al}_{12}$ phase in SEM.

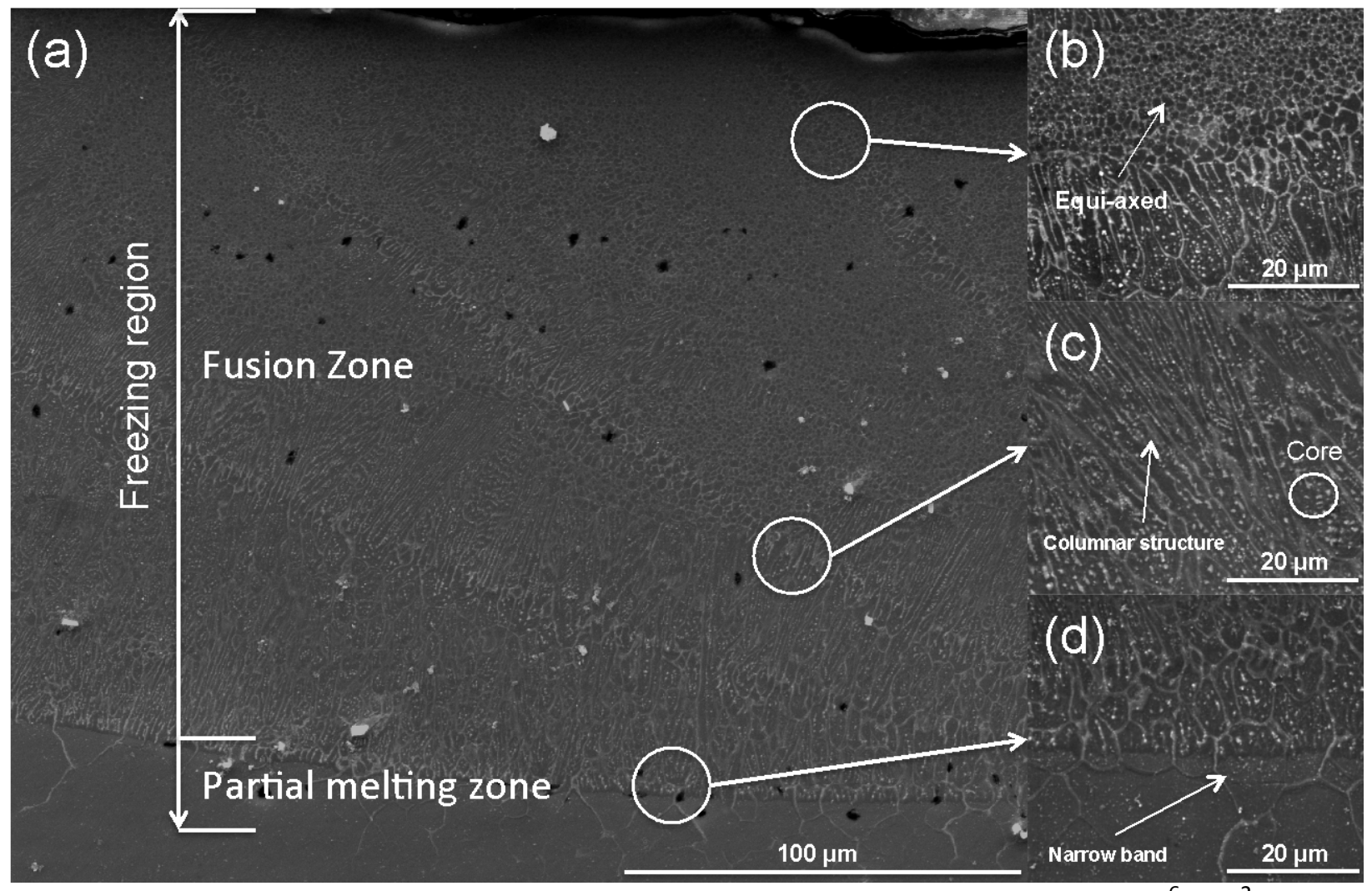

Figure 4.3 Cross-section SEM images of laser surface process sample with $5.31 \times 10^{6} \mathrm{~J} / \mathrm{m}^{2}$ (a) low magnification of freezing region, (b) top region of $F Z$, (c) middle region of $F Z$, and (d) interface of $F Z$ and $P M Z$ 


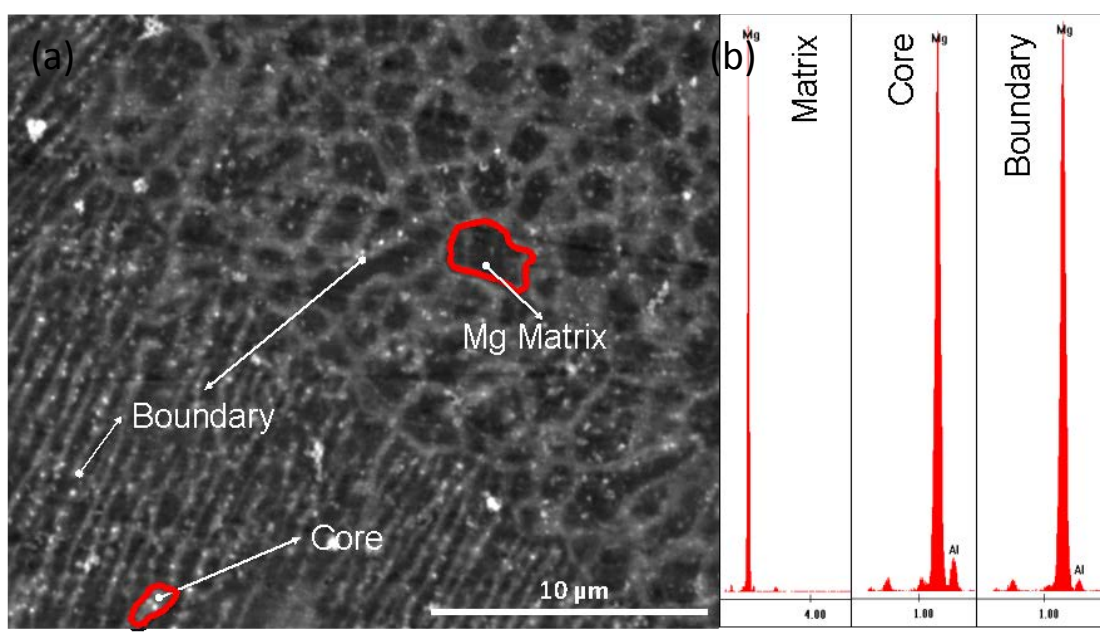

Figure 4.4 (a) SEM backscatter image and (b) EDS analysis results

Because grain size and area of grain boundary within the surface influence the surface energy and wettability, the change of grain size of the fusion zone via laser surface process was measured. Fig. 4.5 shows the SEM images of five laser processing conditions. Because the higher laser energy density was applied to the material, the higher cooling rate and solidification rate were experienced in the freezing zone (Table 4.1). Therefore, knowing the cooling rate and the solidification rate can help in understanding the microstructure evaluation. Fig. 4.6 demonstrates the correlation of laser energy density, cooling rate, and grain size. The results of experimental statistics reveal that in the lowest laser energy density $\left(1.06 \times 10^{6} \mathrm{~J} / \mathrm{m}^{2}\right)$ the average and standard deviation of grain size is large. With an increase in the laser energy density, the average grain size of the fusion zone decreases due to the solidification rate becoming larger. In addition, in higher laser energy density conditions, the population of equiaxed increased, which it indicated that a higher energy input resulted in temperature gradient reduction. 


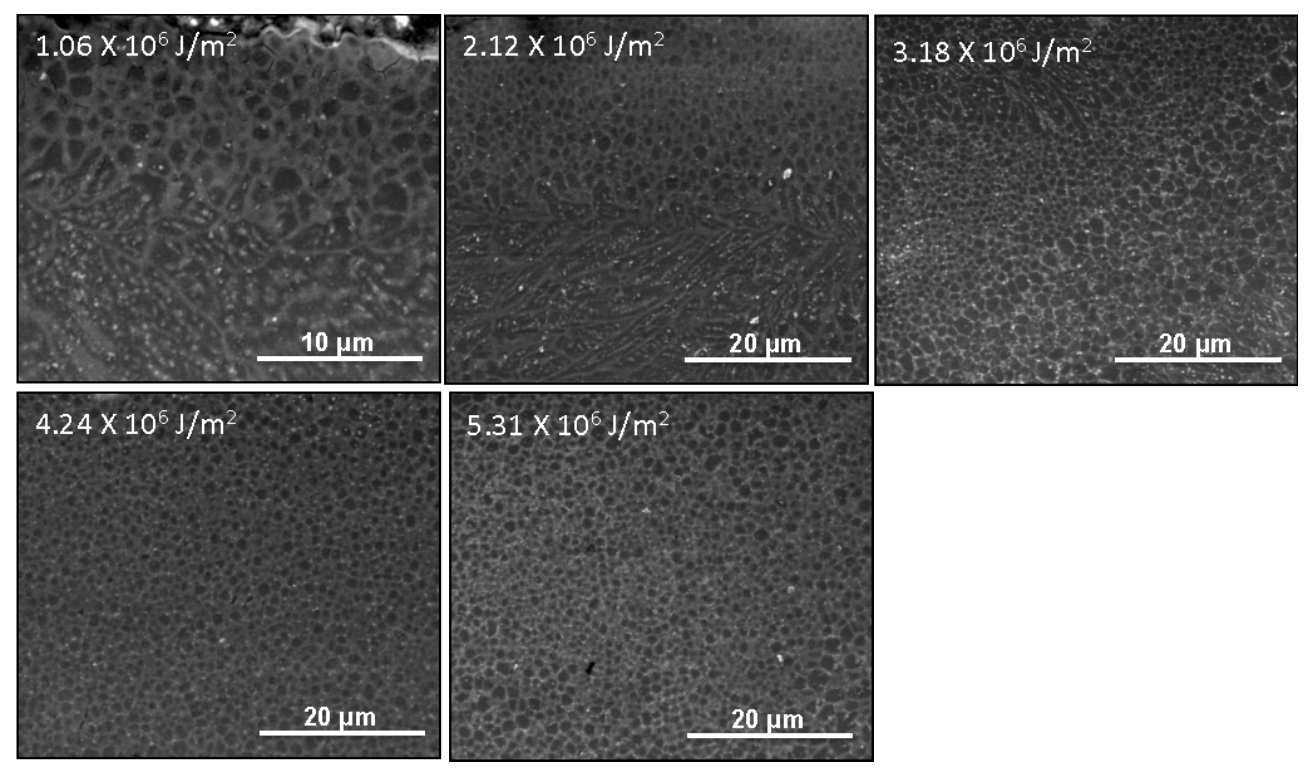

Figure 4.5 Cross-section SEM images of all varation laser processing condition samples

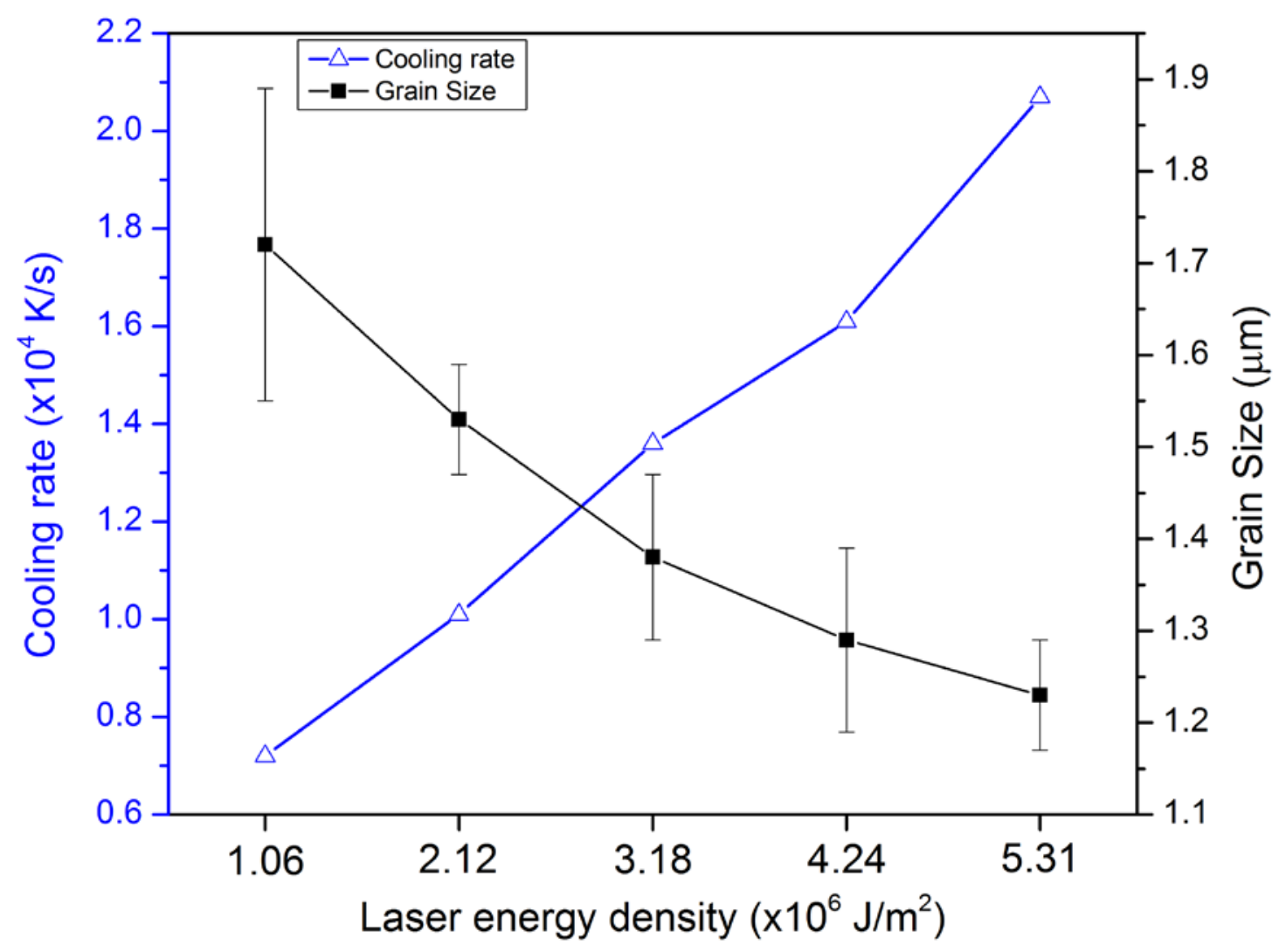

Figure 4.6 Cooling rate and grain size varation plot of all laser process conditions 
The correlation of microstructure observation, phase diagram, and temperature profile can describe the evaluation of microstructures during solidification. Fig. 4.7(a) shows the temperature profile with marks for different stages during solidification process, and Fig. 4.7(b) is the schematic binary $\mathrm{Mg}$-Al phase diagram with important temperatures. In stage $1, \alpha-\mathrm{Mg}$, which possesses a higher melting point, is first transferred into a solid state. Because the liquid's temperature at solid-liquid interface is lower than at the top center of the melt pool, solidification perform to begin at the solid-liquid interface. Furthermore, due to the higher solidification rate perpendicular to the surface than parallel to the surface, portions of the solid-liquid interface grew into liquid, resulting columnar structure in the initial stage of solidification. In the meanwhile, the low melting point of Al was rejected from the interface by the freezing $\alpha-M g$. However, the rapid cooling rate caused Al which had not enough time for diffusion and formed a uniform distribution. Thus in stage 5 , Al started to solidify and tends to grow $\beta-\mathrm{Mg}_{17} \mathrm{Al} \mathrm{I}_{12}$ along $\alpha-\mathrm{Mg}$ grain boundary or to form a core with the grain. In the meanwhile, the remaining $\alpha-M g$ liquid solidified and formed an equi-axed structure owing to the low temperature gradient. Because the laser track overlay, part of the FZ experienced re-melting. It can be observed in the cross section SEM images that by increasing the laser energy density, more overlay area is constituted by the FZ. This fact may be the reason that in the top region of the FZ the $\alpha-\mathrm{Mg}$ prefers to grow in an equi-axed structure instead of a columnar, and reduces the grain size of $\alpha-M g$. Finally, in state 6 all the liquid is transferred into a solid state.

In conclusion, the instantly heating, melting, rapidly cooling and solidifying nature of the laser process plays as the driving force in microstructure evaluation. Fig. 4.8 shows the plots that reveal the tendency of microstructures regarding temperature gradient and solidification 
rate [25]. Based on the thermal model results and the SEM images, the columnar structure mainly grows in the initial solidification at the solid-liquid interface due to the higher temperature gradient. An equi-axed structure distributing in the top region of the FZ indicates that in the further solidifying process the temperature gradient of the melting pool decreases. In higher laser energy density conditions, the temperature is more uniform in the laser track overlay, that is, the temperature gradient is smaller. Therefore, more equi-axed grains were distributed in the FZ due to the faster cooling rate. SEM backscatter images and phase diagram are the clearly evidence that $\beta-M g_{17} \mathrm{Al}_{12}$ mainly grows as core with the grains and at the brain boundary. In addition, the smaller grain size leads more grain boundary area, which causes more heterogeneity with the surface and influences surface wettability.
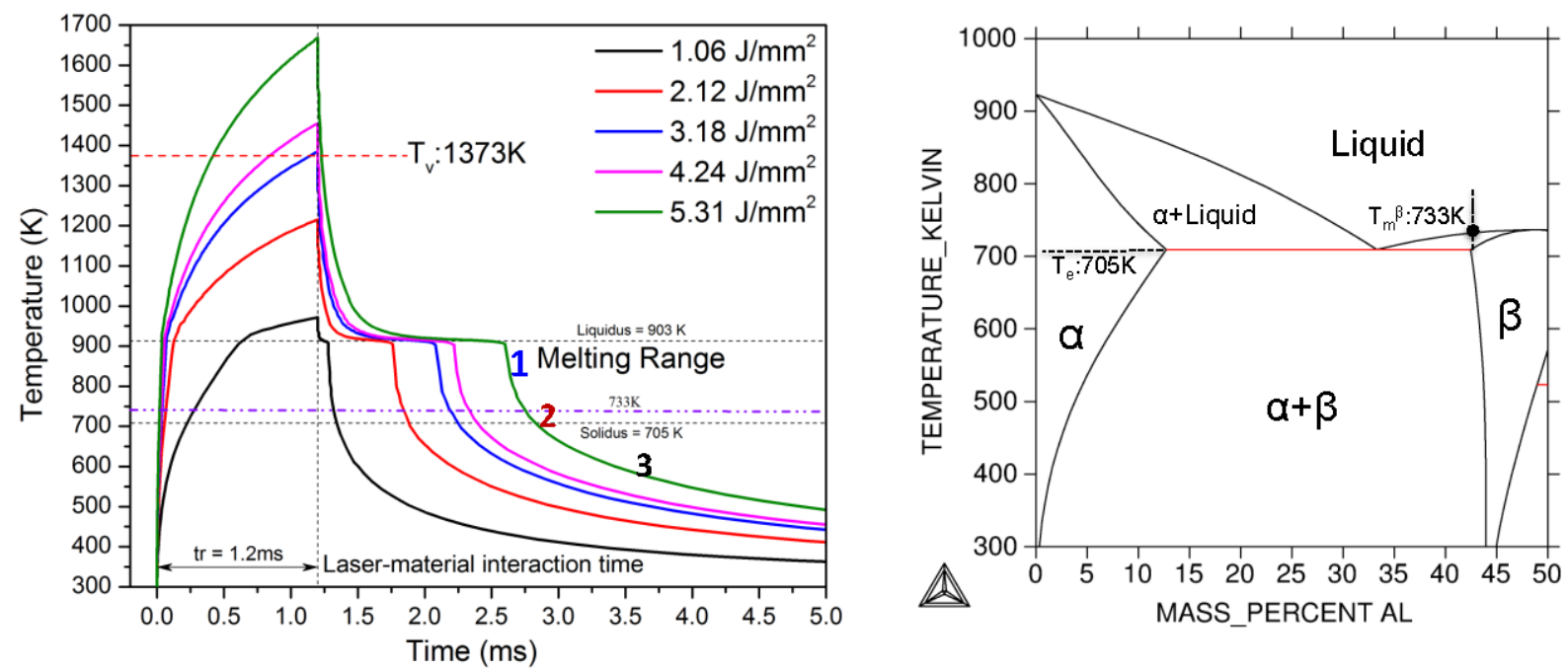

Figure 4.7 (a) Temperatureprofile with solidification stages and (b) binary Mg-Al phase diagram 


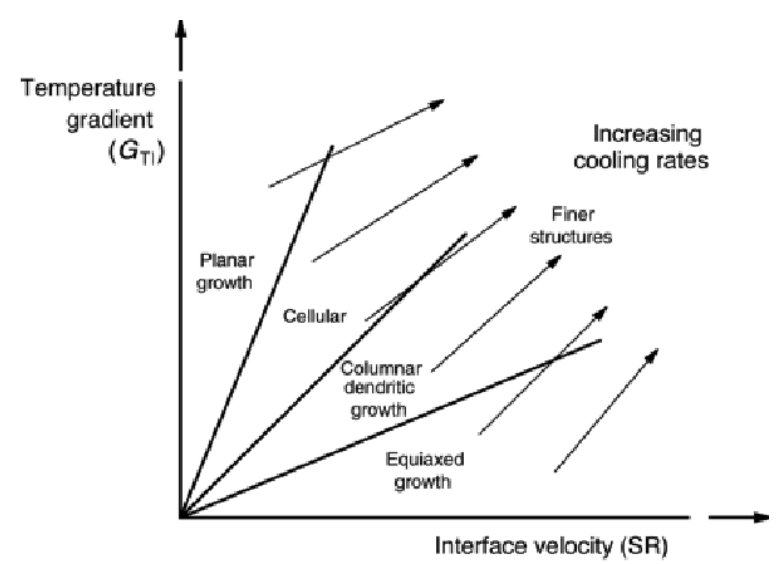

Figure 4.8 Denpendence of solidification structure on liquid temperature gradient and solidification rate

\subsubsection{X-ray Diffraction (XRD)}

Fig. 4.9 is the XRD pattern of all laser processing condition sample and as-receive AZ31B. While the $\alpha-\mathrm{Mg}$ with the hexagonal close packed (hcp) crystal structure is the dominant phase for all five processing conditions and as-received $A Z 31 B$, and $\beta-M g_{17} A I_{12}$ is body centered cubic (bcc) crystal structure. Before laser process only $\alpha$-phase peaks be identified in AZ31B. In addition, $\alpha$-phase peaks shows high intensity and narrow peak width at (002) and (101). After laser process, (002) and (101) peaks of all five laser processing condition samples show lower peak intensity and broad peak width, and the intensity of (100) peak increases. It is because the rapid cooling cycle after laser process leads the change of lattice constants. There is no $\beta$ $M g_{17} A I_{12}$ peak been found in all five XRD pattern. This indicates that the volume of $\beta-M_{17} A I_{12}$ contain is small in the surface. Furthermore, due to the fast solidification there were not enough time for $\beta-\mathrm{Mg}_{17} \mathrm{Al}_{12}$ to grow and diffuse but form precipitates with small size within grain boundaries and cores. This fact also corresponds to the results of EDS analysis. 


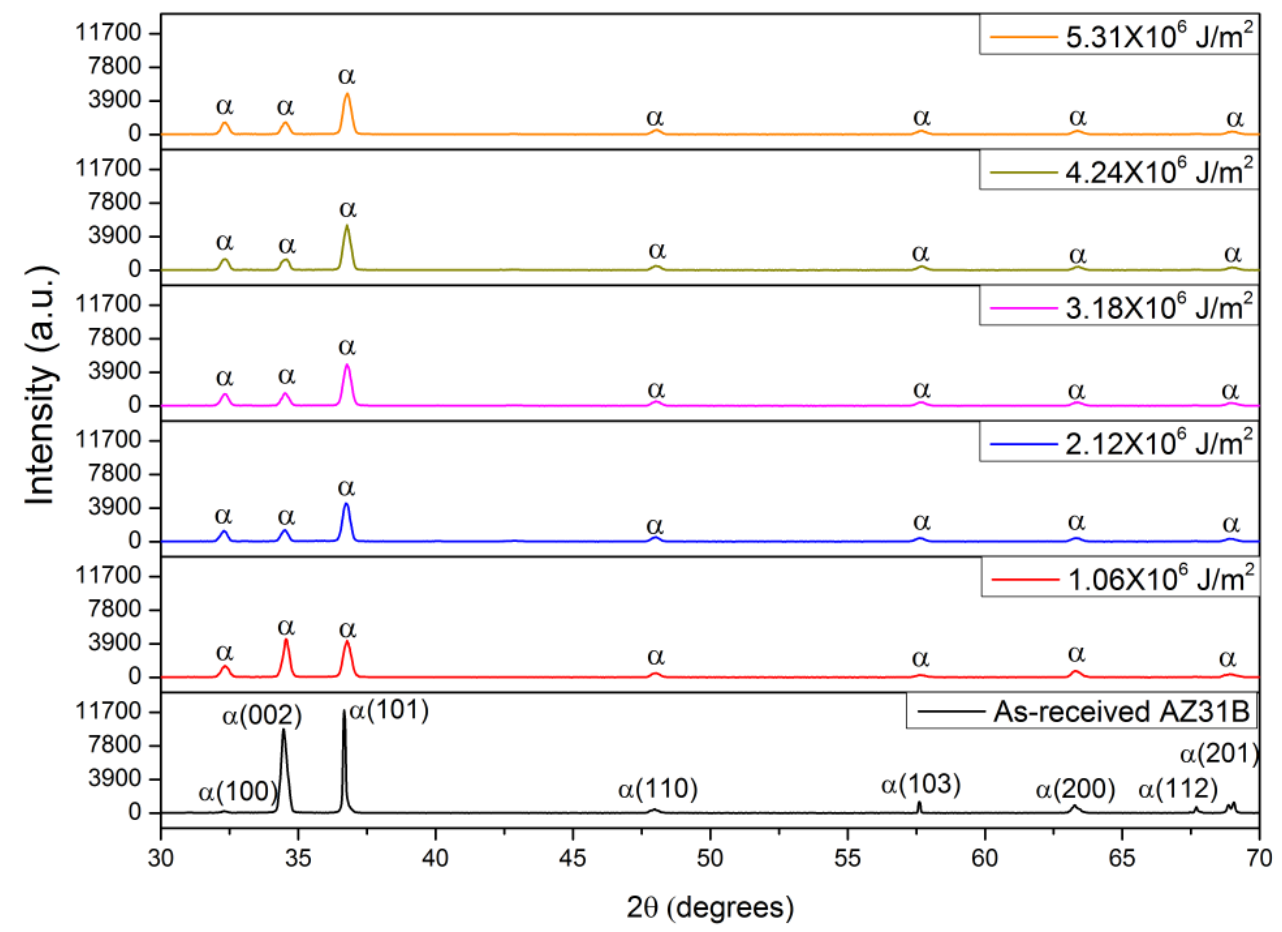

Figure 4.9 XRD pattern of as-received AZ31B Mg and all varation laser processing conditions sample

\subsubsection{Optical Perfilometer}

Fig. 4.10 displays the three-dimensional surface morphology of the as-received AZ31B with fine polishing and five samples of laser processing conditions. The lowest laser energy density condition sample obtains the smoothest surface finish compared to other conditions. It can also be observed that with increasing energy power, the texture structure becomes more significant. Table 4.3 shows the roughness parameters of processing a sample in area arithmetic mean height $\left(S_{a}\right)$ and area root mean square height $\left(S_{q}\right)$. It is clearly seen that in the last two laser energy density conditions, samples obtain significantly higher values of $S_{a}$ and $S_{q}$ as compared to the other laser processing conditions. It is because with increasing laser power the depth of melt in the surface increases. Furthermore, according to the temperature plot (Fig. 
4.1), the sample with two last laser processing conditions, even experiences vaporization. That is, the higher laser power process removes more material, generates deeper village and higher roughness parameter.

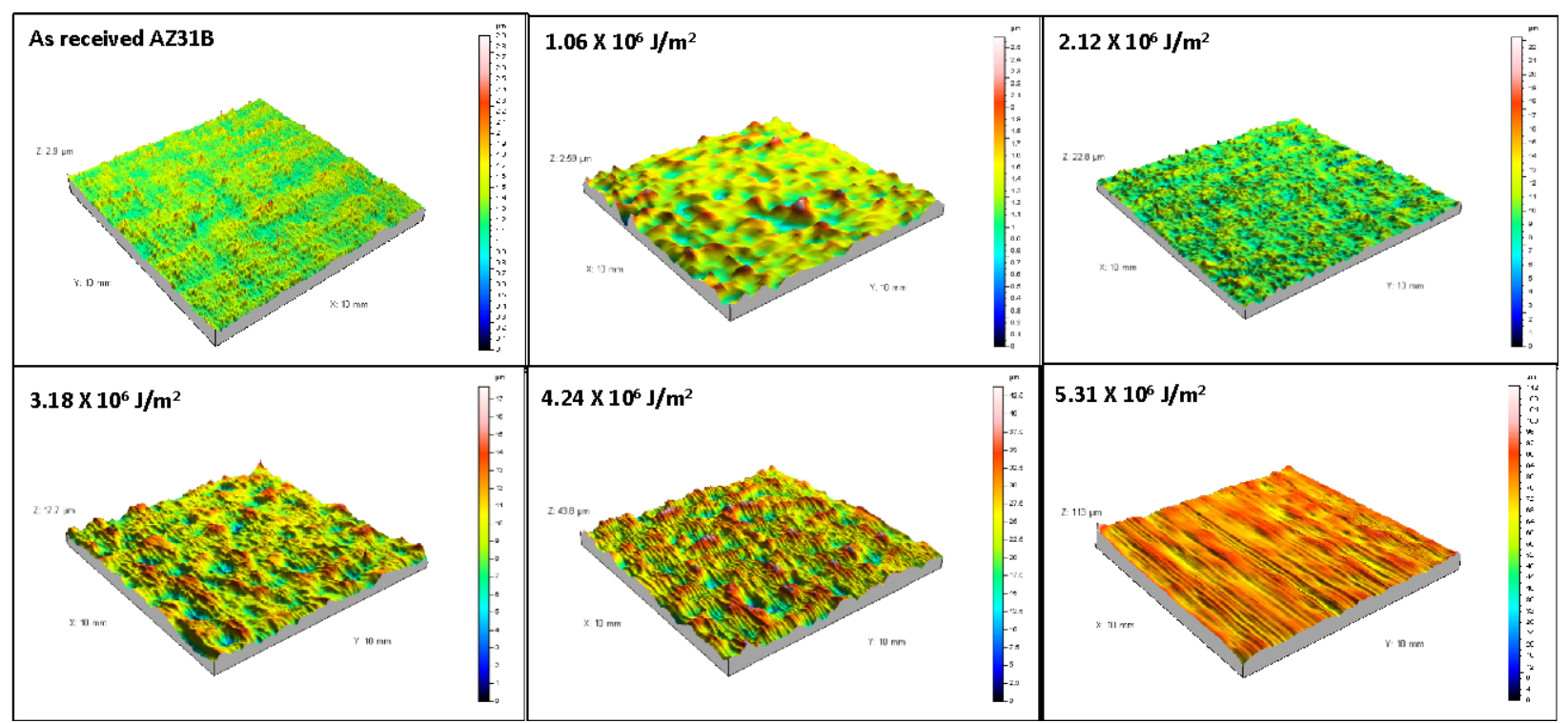

Figure 4.10 Three-dimensional surface morphology of as-received AZ31B and all varation laser surface modification sample

Table 4.3 The results of surface roughness parameters of all laser process samples

\begin{tabular}{ccc}
\hline $\begin{array}{c}\text { Laser Processing Condition } \\
\left(\times 10^{6} \mathrm{~J} / \mathrm{m}^{2}\right)\end{array}$ & $\begin{array}{c}\text { Arithmetic mean height } \\
\left(\mathrm{S}_{\mathrm{a}}, \mu \mathrm{m}\right)\end{array}$ & $\begin{array}{c}\text { Root mean square height } \\
\left(\mathrm{S}_{\mathrm{q}}, \mu \mathrm{m}\right)\end{array}$ \\
\hline As Received AZ31B & $0.08 \pm 0.01$ & $0.11 \pm 0.01$ \\
1.06 & $0.22 \pm 0.24$ & $0.29 \pm 0.24$ \\
2.12 & $0.98 \pm 0.28$ & $1.26 \pm 0.28$ \\
4.18 & $1.38 \pm 0.31$ & $1.79 \pm 0.31$ \\
5.24 & $3.95 \pm 0.24$ & $5.04 \pm 0.24$ \\
\hline
\end{tabular}

\subsection{Effect of Surface Characteristics on Wettability}

Table 4.4 lists the experimental contact angles subtended by three different liquids (water, formamide and 1-bromonaphthalene) on each of these surfaces. By using Eq (1), Eq (2), and $\mathrm{Eq}(3)$, the results of the contact angle are used to calculate the total surface energy. All 
five laser processing conditions show higher surface energy than as received AZ31B. Initially the surface energy enlarges with increasing laser energy density. The calculation results show that $2.12 \times 10^{6} \mathrm{~J} / \mathrm{m}^{2}$ laser processing condition sample obtains the highest surface energy as comparing to other processing conditions. Then the surface energy slightly drops down with further increasing laser energy density. In order to investigate the correlation of the roughness, surface energy, and contact angle, Fig. 4.11 was plotted to demonstrate the trend of changing surface energy, roughness parameter $\left(\mathrm{S}_{\mathrm{q}}\right)$, and the SBF contact angle measurement. The SBF contact angle first reduces with increasing laser energy density. It corresponds to the trend of the increasing surface energy. $2.12 \times 10^{6} \mathrm{~J} / \mathrm{m}^{2}$ laser processing condition sample exhibits the lowest SBF contact angle, that is, this process condition perform most hydrophilic as comparing to other processing conditions. Then with increase laser energy density, the surface energy of the sample reduces, and the SBF contact angle increases. The last two laser processing condition samples preform as the most hydrophobic surface, even close to as-received AZ31B surface wetting performance. Fig. 4.11 also shows that the surface energy and SBF contact angle change are not matched to the surface roughness trend. To explain this phenomenon it is necessary to consider the effect issue of grain size effect on wettability. Since the grain size reduced with increase laser energy density, the grain boundary area is also increased. Further more, these grain boundaries exhibit high concentration of Al. Grains and grain boundaries will react with bio molecule differently. That is, the surface with smaller grain size and larger grain boundary area cause more heterogeneity surface. Table 4.5 demonstrates the results of SBF contact measurement, surface energy, roughness parameter, and surface average grain size. It can be seem that when the surface which obtains low $S_{q}$ and larger grain size perform more 
hydrophilicity; the surface which obtains high $\mathrm{S}_{\mathrm{q}}$ and small grain size perform more hydrophobicity. This face also explains that the surface wettability is the complex phenomena, several factors affect the interactions between bio molecule and surface. Further more, it is hard to say which factor plays a role in effect of surface wettability.

Table 4.4 Experimental results of contact angle of test liquids, surface energy components, and surface energy as function of sample processing conditions

\begin{tabular}{ccccccc}
\hline & \multicolumn{2}{c}{ Contact angle measurement } & $\begin{array}{c}\text { Surface } \\
\text { energy } \\
\text { components }\end{array}$ & $\begin{array}{c}\text { Total surface } \\
\text { energy } \\
\left(\mathrm{mJm}^{-2}\right)\end{array}$ \\
\cline { 2 - 7 } $\begin{array}{c}\text { Sample } \\
\text { processing } \\
\text { condition } \\
\left(\times 10^{6} \mathrm{~J} / \mathrm{m}^{2}\right)\end{array}$ & D.I water & Formamide & 1-Bromonaphthalene & $\gamma^{\mathrm{LW}}$ & $\gamma^{\mathrm{AB}}$ & $\gamma^{\text {total }}$ \\
\hline As-received & $72.9 \pm 3.01$ & $59.6 \pm 2.62$ & $35.0 \pm 2.12$ & 36.70 & 1.22 & 37.91 \\
AZ31B & & & & & & \\
1.06 & $47.7 \pm 4.31$ & $41.7 \pm 5.73$ & $20.0 \pm 4.20$ & 41.72 & 4.35 & 41.72 \\
2.12 & $48.4 \pm 4.94$ & $39.4 \pm 4.00$ & $19.5 \pm 6.34$ & 41.89 & 6.03 & 47.88 \\
3.18 & $46.1 \pm 4.11$ & $40.3 \pm 4.47$ & $18.8 \pm 4.6$ & 42.06 & 4.75 & 46.77 \\
4.24 & $53.6 \pm 4.45$ & $43.4 \pm 3.85$ & $23.4 \pm 4.36$ & 40.78 & 5.20 & 45.98 \\
5.31 & $61.4 \pm 6.89$ & $47.8 \pm 4.77$ & $24.9 \pm 3.99$ & 40.33 & 4.08 & 40.33 \\
\hline
\end{tabular}




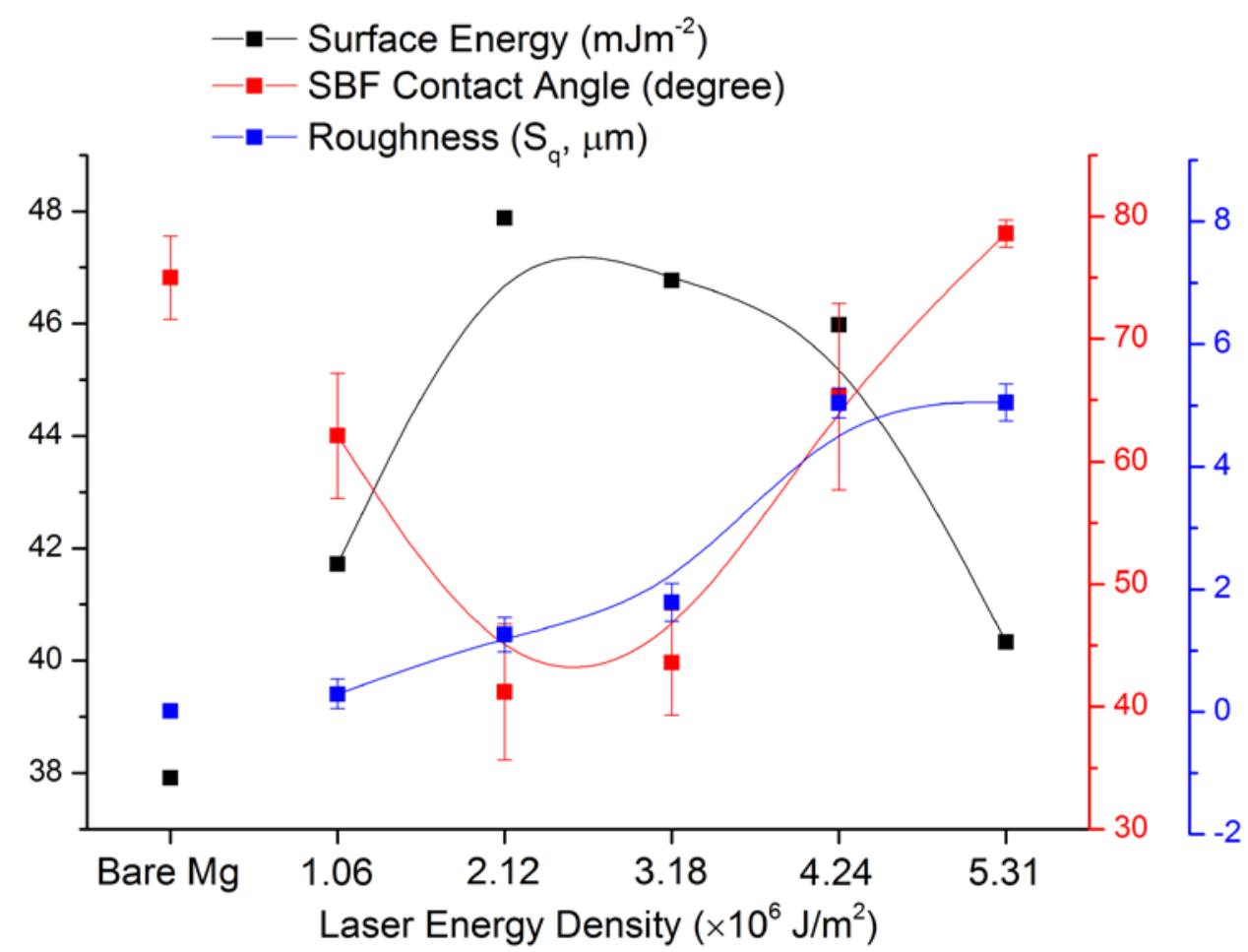

Figure 4.11 The plots of surface energy, SBF contact angle, and roughness varation with different laser processing conditions

Table 4.5 The comparison of SBF contact angle, roughness parameter, surface energy, and surface average grain size of five laser process conditions

\begin{tabular}{ccccc}
\hline $\begin{array}{c}\text { Laser } \\
\text { Processing } \\
\begin{array}{c}\text { condition } \\
\left(\mathrm{x} 10^{6} \mathrm{~J} / \mathrm{m}^{2}\right)\end{array}\end{array}$ & $\begin{array}{c}\text { SBF Contact Angle } \\
\text { (degree) }\end{array}$ & $\begin{array}{c}\text { Roughness } \\
\left(\mathrm{S}_{\mathrm{q}}, \mu \mathrm{m}\right)\end{array}$ & $\begin{array}{c}\text { Surface Energy } \\
\left(\mathrm{mJm}^{-2}\right)\end{array}$ & $\begin{array}{c}\text { Average Grain Size } \\
(\mu \mathrm{m})\end{array}$ \\
\hline 1.06 & $62.1 \pm 5.11$ & $0.29 \pm 0.24$ & 41.72 & $1.72 \pm 0.17$ \\
2.12 & $41.2 \pm 5.53$ & $1.26 \pm 0.28$ & 47.88 & $1.53 \pm 0.06$ \\
3.18 & $43.6 \pm 4.29$ & $1.79 \pm 0.31$ & 46.77 & $1.38 \pm 0.09$ \\
4.24 & $65.3 \pm 7.62$ & $5.04 \pm 0.24$ & 45.98 & $1.28 \pm 0.1$ \\
5.31 & $78.6 \pm 1.11$ & $5.05 \pm 0.3$ & 40.33 & $1.23 \pm 0.06$ \\
\hline
\end{tabular}




\section{CHAPTER 5}

\section{SUMMARY AND CONCLUSION}

The results of the microstructure observation, chemical composition analysis, roughness evaluation, surface energy calculation, and SBF contact angle measurement demonstrate that laser surface modification of AZ31B Mg provides a great incentive for creating a hydrophobic/hydrophilic surface for bio-application. The use of high energy laser allows the surface to reach the temperature above melting point of $\alpha-M g$ phase and $\beta-M_{17} \mathrm{Al}_{12}$ phase. Furthermore, higher laser energy will additionally cause vaporization of material to generate a high roughness surface. COMSOL Multiphysics was used to calculate the surface temperature variation, cooling rate, temperature gradient, and solidification rate during the laser process. Based on the modeling result, the processing laser power conditions were designed for surface modification. During the solidification process, $\alpha-\mathrm{Mg}$ phase experiences rapid temperature dropping, to grow first as columnar and equi-axed structure. The temperature gradient and solidification rate are the controlling factors that determine the microstructure of $\alpha-\mathrm{Mg}$. In the meanwhile, $\beta-\mathrm{Mg}_{17} \mathrm{Al}_{12}$ prefers to form precipitates along $\alpha-\mathrm{Mg}$ grain boundary or core within the grain because of the low melting point of $\beta-\mathrm{Mg}_{17} \mathrm{Al}{ }_{12}$ and the rapidly cooling process of material. With increased laser energy density by an increase in laser power, the size of the $\mathrm{FZ}$ becomes larger, and the distribution of the euqi-axed structure and $\beta-\mathrm{Mg}_{17} \mathrm{Al}_{12}$ precipitate increases. However, due to the limitation of characteristic instrument the quantification of $\beta$ $\mathrm{Mg}_{17} \mathrm{Al}_{12}$ is unknown.

In this study, the most important characteristics to influence wettability is surface

roughness and average grain size. Using high laser energy technique is a quick process to 
generate surface texture structure on biomaterial. Due to the melting and vaporization, the processing surface will become rougher with increasing laser power. It should be note that if the surface temperature exceeds the vaporization during laser process the finishing surface roughness will increase rapidly. The high laser process also causes the fast cooling and reduces the grain size in the surface. The high solidification and low temperature gradient lead the uniform grains and great grain boundary area.

The performance of wettability of the laser surface modification sample highly matches to surface energy calculation. The surface with low surface energy performs as hydrophobic surface, and the surface with high surface energy perform as hydrophilic surface. The surface roughness and average grain size will directly affect to surface wetting performance. The low roughness and larger grain size surface performs more hydrophilic, and the high roughness and small grain size surface performs more hydrophobic. In conclusion, the laser surface modification of AZ31B Mg alloy changes the surface wettability; these modifications will influence the interaction rate between the implant surface and bio-fluid within the human body. 


\section{CHAPTER 6}

\section{FURTHER WORK}

\subsection{Corrosion Experiment}

$\beta-\mathrm{Mg}_{17} \mathrm{Al}_{12}$ has been reported to it can play as an anti-corrosion barrier during corrosion. Because $\mathrm{Mg}$ alloy possesses a rapid degrade rate in a biological environment, it is critical to improve corrosion resistance of $\mathrm{Mg}$ to match the needs of implant application. In this study, AZ31B Mg-based alloy with laser surface modification exhibits $\beta-M_{17} \mathrm{Al}_{12}$ precipitates at grain boundary and within grain. Therefore, the corrosion behavior and degradation mechanism regarding laser processing of $\mathrm{AZ31B}$ in the bio-environment are the interesting issues to investigate.

\subsection{In Vitro Bioactivity and in Vitro Biocompatibility}

The purpose of designing three-dimensional features on biomaterial is for surface to react with the molecules in the body environment, in order to form an imitated biological film on the surface to absorb protein and cells. The bioactivity and the mineralization kinetics of laser process AZ31B in the biological environment have not been investigated. Therefore, further bio-mineralization evaluation of laser surface modification AZ31B will be carried out. In addition, this evaluation result can correlate to the contact angle measurement to further understand the association of surface energy and bio-mineralization.

Cell attachment and cell absorption are most important characteristics of moleculesurface reaction for implant designing. A successful bio-implant should obtain strong bonding between surface and cell. Also, the livability of the cell on the implant surface should be 
improve in order to prevent the tissue fall occur after implantation. In vitro biocompatibility evaluation is aimed at cell attachment and cell morphology during cell culture. 


\section{REFERENCE}

[1] N. Erdmann, N. Angrisani, J. Reifenrath, A. Lucas, F. Thorey, D. Bormann and A. MeyerLindenberg, '"Biomechanical testing and degradation analysis of $\mathrm{MgCaO} .8$ alloy screws: $\mathrm{A}$ comparative in vivo study in rabbits," Acta Biomaterialia, vol. 7, no. 3, 03, pp. 1421-8.

[2] J. Gray-Munro and M. Strong, '"The mechanism of deposition of calcium phosphate coatings from solution onto magnesium alloy AZ31," Journal of Biomedical Materials Research - Part A, vol. 90, no. 2, pp. 339-350.

[3] J. Gray-Munro, C. Seguin and M. Strong, '"Influence of surface modification on the in vitro corrosion rate of magnesium alloy AZ31," Journal of Biomedical Materials Research - Part A, vol. 91 , no. 1, pp. 221-230.

[4] X. Gu, Y. Zheng, Y. Cheng, S. Zhong and T. Xi, '"In vitro corrosion and biocompatibility of binary magnesium alloys," Biomaterials, vol. 30, no. 4, 02, pp. 484-98.

[5] A.M. Pietak, M.P. Staiger, J. Huadmai and G. Dias, '"Magnesium and its alloys as orthopedic biomaterials: A review," Biomaterials, vol. 27, no. 9, 03, pp. 1728-34.

[6] Xue-Nan Gu and Yu-Feng Zheng, '"A review on magnesium alloys as biodegradable materials," Frontiers of Materials Science in China, vol. 4, no. 2, 06, pp. 111-15.

[7] B.R. Sunil, A.A. Kumar, T.S. Sampath Kumar and U. Chakkingal, '"Role of biomineralization on the degradation of fine grained AZ31 magnesium alloy processed by groove pressing," Materials Science and Engineering C, vol. 33, no. 3, pp. 1607-1615.

[8] M.B. Kannan and R.K.S. Raman, '"In vitro degradation and mechanical integrity of calciumcontaining magnesium alloys in modified-simulated body fluid," Biomaterials, vol. 29, no. 15, pp. 2306-2314.

[9] S.S. Guangling Song, '"A Possible Biodegradable Magnesium Implant Material," Advanced Engineering Materials, vol. 9, no. 4, pp. 298-320.

[10] A. Abdal-hay, N.A.M. Barakat and J.K. Lim, '"Hydroxyapatite-doped poly(lactic acid) porous film coating for enhanced bioactivity and corrosion behavior of AZ31 Mg alloy for orthopedic applications," Ceram.Int., vol. 39, no. 1, 1, pp. 183-195.

[11] Y.C. Guan, W. Zhou and H.Y. Zheng, '"Effect of laser surface melting on corrosion behaviour of AZ91D Mg alloy in simulated-modified body fluid," J.Appl.Electrochem., vol. 39, no. 9, pp. 1457-1464. 
[12] W. Zhou, T. Shen and N.N. Aung, '"Effect of heat treatment on corrosion behaviour of magnesium alloy AZ91D in simulated body fluid," Corros.Sci., vol. 52, no. 3, pp. 1035-1041.

[13] L. Xu and C.A. Siedlecki, '"Effects of surface wettability and contact time on protein adhesion to biomaterial surfaces," Biomaterials, vol. 28, no. 22, pp. 3273-3283.

[14] S.R. Paital and N.B. Dahotre, '"Calcium phosphate coatings for bio-implant applications: Materials, performance factors, and methodologies," Materials Science and Engineering $R$ : Reports, vol. 66, no. 1-3, pp. 1-70.

[15] S.R. Paital, Z. Cao, W. He and N.B. Dahotre, '"Wetting effects on in vitro bioactivity and in vitro biocompatibility of laser micro-textured Ca-P coating," Biofabrication, vol. 2, no. 2, 06, pp. 025001 (14 pp.).

[16] S.R. Paital and N.B. Dahotre, '"Wettability and kinetics of hydroxyapatite precipitation on a laser-textured Ca-P bioceramic coating," Acta Biomaterialia, vol. 5, no. 7, pp. 2763-72.

[17] Z. Ma, Z. Mao and C. Gao, '"Surface modification and property analysis of biomedical polymers used for tissue engineering," Colloids and Surfaces B: Biointerfaces, vol. 60, no. 2, pp. 137-157.

[18] Xiao Dong-Ming, Yang Yong-Giang, Su Xu-bin, W. Di and Luo Zi-yi, '"Topology optimization of microstructure and selective laser melting fabrication for metallic biomaterial scaffolds," Transactions of Nonferrous Metals Society of China, vol. 22, no. 10, 10, pp. 2554-61.

[19] C.C. Ng, M.M. Savalani, M.L. Lau and H.C. Man, '"Microstructure and mechanical properties of selective laser melted magnesium," Appl.Surf.Sci., vol. 257, no. 17, pp. 7447-7454.

[20] C. J. Van Oss , R. J. Good, M. K. Chaudhury, "'Additive and nonadditive surface tension components and the interpretation of contact angles," Langmuir, vol. 4 (4), pp. 884-891.

[21] S. Bargir, S. Dunn, B. Jefferson, J. Macadam and S. Parsons, '"The use of contact angle measurements to estimate the adhesion propensity of calcium carbonate to solid substrates in water," Appl.Surf.Sci., vol. 255, no. 9, 2/15, pp. 4873-4879.

[22] C.D. Cox, "'Friction Stir Welded Magnesium Alliy AZ31B in a Lap Joint Configuration," Master thesis, Vanderbilt University.

[23] P. Guo, X. Zhang, H. Hao and J. Jin, '"Temperature simulation of direct chill casting of AZ31B magnesium alloy billets," The Chinese Journal of Nonferrous Metals, vol. 16, no. 9, pp. 15701576. 
[24] D. Zhang, Q. Dai, L. Fang and X. Xu, '"Prediction of edge cracks and plastic-damage analysis of Mg alloy sheet in rolling," Transactions of Nonferrous Metals Society of China, vol. 21, no. 5, 5, pp. 1112-1117.

[25] J. Elijah Kannatey-Asibu, '"Principles of Laser Materials Processing,", pp. 295. 